\title{
Career Fire Fighter/Engineer Dies After Falling Through Translucent Corrugated Roof Panel While Searching for Fire Extension-Colorado
}

\section{Executive Summary}

On June 28, 2015, a 46-year-old male career fire fighter/engineer was critically injured after falling through a translucent corrugated roof panel. The fire fighter was the engineer on Truck 8, the third truck company dispatched to a possible structure fire at a multipurpose commercial structure at 2132 hours. The first arriving companies found an exterior dumpster on fire with flames extending approximately 4 feet up the exterior sheet-metal wall along the edge of an exterior window. District Chief 2 arrived on-scene and assumed incident command (IC) just as the dumpster was being pulled away from the structure. Fire fighters quickly

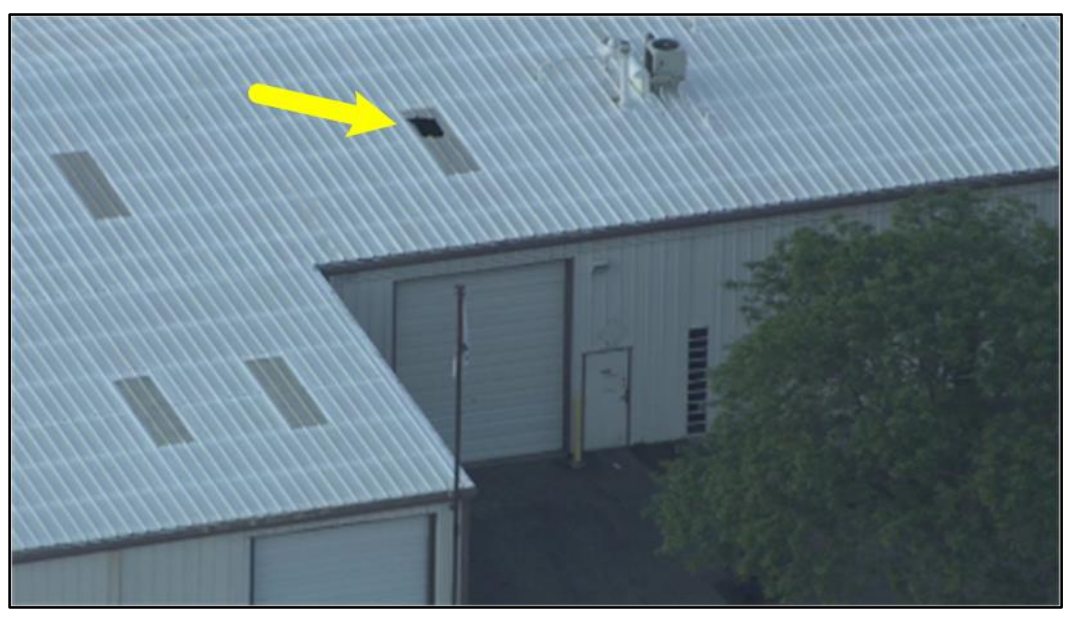

Location on roof where 46-year-old Truck 8 engineer fell through a translucent corrugated roof panel. Note how translucent roof panels blend in with rest of roof. (Photo courtesy of fire department.)

extinguished the fire in the dumpster using a booster hose. The IC directed crews to force entry into the structure to conduct an interior search for occupants and fire extension. The IC also directed the Truck 8 crew to the roof to check for fire extension. All searches were negative. The IC requested that the Truck 8 crew size up the approximate building dimensions. While reporting the building dimensions to the incident commander, the Truck 8 engineer stepped onto a translucent corrugated roof panel, which cracked under his weight. The roof was not well illuminated and the translucent panel blended with the rest of the roof. He fell approximately 17 feet onto the concrete floor below. The engineer suffered multiple open bone fractures and vascular damage. He was immediately transported to a trauma hospital (Hospital 1) where multiple surgeries were performed over a 2-week period. On July 9, 2015, the engineer was discharged from the hospital to continue his recovery at home. On July 15, six days after discharge, the engineer experienced sudden onset of severe shortness of breath. He was transported by ambulance to Hospital 2, but upon arrival in the hospital's parking lot, he suffered a cardiopulmonary arrest. Efforts to resuscitate the engineer in the hospital's emergency department were unsuccessful. An autopsy revealed a massive pulmonary thromboembolism originating from a thrombus in his lower extremity formed as a result of blunt trauma injuries sustained during his fall. The pulmonary thromboembolism occurred despite being on anticoagulation therapy. 


\section{Career Fire Fighter/Engineer Dies After Falling Through Translucent Corrugated Roof Panel While Searching for Fire Extension-Colorado}

\section{Contributing Factors}

- Unrecognized fall hazard associated with walking on translucent corrugated roof panels.

- Low light conditions on the roof.

- Engineer distracted by talking on the radio while walking on the roof.

- Roof crew did not continuously sound the roof.

- Previous near-miss incident not effectively reported as a learning tool.

- Translucent roof panels do not require the same load bearing or fall resistance performances in the International Building Codes as scuttles or skylights.

- Translucent roof panels, skylights, or scuttles may not be identifiable from roof panels.

\section{Key Recommendations}

- Fire departments should ensure that all fire fighters, company officers, and chief officers are aware of and trained to recognize translucent corrugated roof panels and the fall hazard these panels present.

- Fire departments should establish policies and procedures to ensure that fire fighters follow safe roof operating practices, including sounding the roof; not walking or standing on translucent corrugated roof panels, scuttles, and skylights; having enough ladders for safe exit in low-light conditions; and always wearing the proper personal protective equipment, including self-contained breathing apparatus.

- Fire departments should ensure that fire fighters are trained in and recognize the importance of situational awareness at all times, including while working on a roof.

- Fire departments should conduct pre-incident planning inspections of buildings within their jurisdictions and include this information in computer-aided dispatch systems to facilitate development of safe fireground strategies and tactics.

Additionally:

- Manufacturers, distributors, and installers of translucent corrugated roof panels should ensure that end users are fully aware of the load-bearing limitations associated with these types of roof panels.

\footnotetext{
The National Institute for Occupational Safety and Health (NIOSH), an institute within the Centers for Disease Control and Prevention (CDC), is the federal agency responsible for conducting research and making recommendations for the prevention of work-related injury and illness. In 1998, Congress appropriated funds to NIOSH to conduct a fire fighter initiative that resulted in the NIOSH "Fire Fighter Fatality Investigation and Prevention Program" which examines line-of-duty-deaths or on duty deaths of fire fighters to assist fire departments, fire fighters, the fire service and others to prevent similar fire fighter deaths in the future. The agency does not enforce compliance with State or Federal occupational safety and health standards and does not determine fault or assign blame. Participation of fire departments and individuals in NIOSH investigations is voluntary. Under its program, NIOSH investigators interview persons with knowledge of the incident who agree to be interviewed and review available records to develop a description of the conditions and circumstances leading to the death(s). Interviewees are not asked to sign swom statements and interviews are not recorded. The agency's reports do not name the victim, the fire department or those interviewed. The NIOSH report's summary of the conditions and circumstances surrounding the fatality is intended to provide context to the agency's recommendations and is not intended to be definitive for purposes of determining any claim or benefit.
}

For further information, visit the program website at www.cdc.gov/niosh/fire or call toll free 1-800-CDC-INFO (1-800-232-4636). 


\section{Career Fire Fighter/Engineer Dies After Falling Through Translucent Corrugated Roof Panel While Searching for Fire Extension-Colorado}

\section{Introduction}

On June 28, 2015, a 46-year-old male career fire fighter/engineer fell through a translucent corrugated roof panel of a commercial building. The engineer was critically injured in the fall. After multiple emergency surgeries and a 2-week hospitalization, the engineer was discharged to continue his recovery at home. Six days after discharge (on July 15, 2015), the engineer experienced a fatal pulmonary thromboembolism originating from a thrombus in his lower extremity formed as a consequence of the fall.

On July 16, 2015, the fire department contacted the National Institute for Occupational Safety and Health (NIOSH) and requested an investigation of this incident. That same day, the U.S. Fire Administration also notified NIOSH of the line-of-duty death. On August 3, 2015, a safety engineer and occupational physician from the NIOSH Fire Fighter Fatality Investigation and Prevention Program and an occupational safety and health specialist and a research assistant from the NIOSH Western States Division traveled to Colorado to investigate the incident. The NIOSH investigation team met with the fire department's senior management staff, along with the International Association of Fire Fighters local union president, to initiate the investigation.

During the investigation, NIOSH personnel contacted/interviewed the following people:

- Fire department members involved with the incident

- Incident commander

- Training and safety chief

- Wellness fitness coordinator

- Training coordinator

- Fire fighters/EMS personnel who transported the fire fighter/engineer on June 28, 2015

- Medical director for the city/county's Center for Occupational Safety and Health

- Ambulance crew responding on July 15, 2015

- City/county medical examiner's office

NIOSH personnel reviewed the following documents:

- Fire department training records

- Fire department annual report for 2013

- Fire department incident report

- Fire department medical program

- Emergency medical service (ambulance) incident reports (for both June 28 and July 9, 2015)

- Emergency department medical records (for both June 28 and July 9, 2015)

- Medical records from the June 28, 2015, hospitalization

- Autopsy report

- Fire fighter/engineer's medical records maintained for the fire department by the city/county. 


\section{Career Fire Fighter/Engineer Dies After Falling Through Translucent Corrugated Roof Panel While Searching for Fire Extension-Colorado}

The NIOSH investigators visited the incident site and took photographs and measurements. They also visited the fire department's training academy, the county's occupational health clinic, and the county's office of the medical examiner.

\section{Fire Department}

The career fire department involved in this incident serves a large metropolitan area in Colorado, a large commercial airport, and four surrounding cities. The response area is 155 miles and serves over 650,000 residents. The fire department also provides mutual aid to 54 municipalities throughout the area. The fire department is rated by the Insurance Services Office as a Class 2 fire department and is Pro-Board Accredited ${ }^{\mathrm{a}}$.

The fire department employs 961 personnel and is organized into six divisions:

- Operations

- Fire Prevention

- Technical Services (includes Fire Dispatch/Communications, Fleet Management, Facilities Management, and Line Shop groups)

- Administration

- Safety and Training (includes a 17-week training academy)

- Airport Division (responsible for providing aircraft rescue fire-fighting to the large commercial airport)

The Operations Division is the largest of the six divisions and employs 763 uniformed members. The Operations Division is responsible for emergency services to residents within the response district on all calls for emergency medical assistance, auto accidents, structure fires, and major disasters. It also provides mutual aid to the surrounding communities. The daily minimum staffing for the Operations Division is 194 personnel. The Operations Division operates on 24/48 work schedule, which equates to a 48-hour workweek with 1 day off (Kelley day) per month, using a 3-platoon system (A Shift, B Shift, and C Shift).

The fire department response area is divided into six geographic response districts. There are 33 fully staffed fire stations within the six geographic response districts and four additional fire stations located at the airport. All fire stations are equipped with at least an engine and truck or tower, and some stations have a combination of apparatus types. Each apparatus is minimally staffed by a company officer, a driver, and two fire fighters. Engine companies are charged with fire suppression, water supply, and primary emergency medical service (EMS) response. Truck companies and tower

\footnotetext{
${ }^{\mathrm{a}}$ The International Services Office (ISO) is an independent commercial enterprise that helps customers identify and mitigate risk. ISO can provide communities with information on fire protection, water systems, other critical infrastructure, building codes, and natural and man-made catastrophes. ISO's Public Protection Criteria program evaluates communities according to a uniform set of criteria known as the Fire Suppression Rating Schedule (FSRS). More information about ISO and their Fire Suppression Rating Schedule can be found at the website https://www.isomitigation.com/.
} 


\section{Career Fire Fighter/Engineer Dies After Falling Through Translucent Corrugated Roof Panel While Searching for Fire Extension-Colorado}

companies carry aerial ladders and ground ladders and perform search and rescue, victim rescue, forcible entry and salvage, and overhaul. Five special operations branches are located at five stations throughout the districts. These branches are made up of a heavy rescue company (Rescue 1), two hazardous materials response teams (HAMER 1 and HAMER 3), a decontamination unit, a collapse and high-angle response team, and an underwater rescue team.

Since the 1990s, city fire fighters have served as fire dispatchers at a combined fire, police, and EMS 9-1-1 communications center. Dispatch staff consists of an assistant chief, a captain, two lieutenants, and 15 dispatch technicians. The assistant chief works a 40-hour week while the captain, two lieutenants, and 15 technicians work rotating 24-hour shifts (A, B, and C).

All fire fighters carry a portable radio that is assigned to the riding position on each apparatus. The fire department uses a standard radio designation scheme based upon apparatus riding positions.

- Apparatus officer-designated Alpha

- Apparatus engineer-designated Bravo

- Senior fire fighter on apparatus_-designated Charlie

- Junior fire fighter on apparatus-designated Delta

For example, the officer on Engine 1 would be designated Engine 1 Alpha, the engineer would be Engine 1 Bravo, the senior fire fighter would be Engine 1 Charlie, and the junior fire fighter would be Engine 1 Delta.

The city's primary EMS provider is managed by the city's health and hospital authority. The EMS provider uses "dynamic ambulance posting," a dispatch system that positions ambulances at different locations throughout the city based on anticipated call volume. At peak times, 26 advanced life support ambulances are available. Each ambulance crew, of at least two medics, works a 10-hour shift. Shifts are staggered to provide 24-hour coverage. The fire department provides "first responder" service to the EMS provider on potentially life-threatening calls (e.g., cardiac, respiratory, trauma, and burn injuries). Fire fighters are certified to the Emergency Medical Technician Basic Life Support level. During a response, the nearest engine or truck responds with an ambulance from the EMS provider.

In 2014, the fire department responded to a total of 112,370 emergency calls, including 1,957 fire calls, 73,553 rescue and emergency medical service (EMS) incidents, and 9,581 false alarm calls. The remaining responses included hazardous conditions calls, service calls, special incident types, and severe weather. The department responded to a total of 147,578 emergency calls in 2013 and 142,958 emergency calls in 2012.

\section{Rank Descriptions}

The rank order rises within the fire department from fire fighter to engineer, lieutenant, captain, assistant chief, division chief, deputy chief, and chief.

\section{Medical Evaluation Program}

The fire department has a mandatory candidate medical evaluation conducted by the County Center for Occupational Safety and Health. The components of the evaluation include two health history forms (Med-Tox and the Fire and Police Pension Association), three questionnaires (Occupational Safety and 


\section{Career Fire Fighter/Engineer Dies After Falling Through Translucent Corrugated Roof Panel While Searching for Fire Extension-Colorado}

Health Administration respiratory medical questionnaire, a hearing conservation questionnaire, and a latex sensitivity questionnaire), a medical examination, blood testing (complete blood count with differential, SMA-20, and a lipid panel), urine dipstick test, spirometry, electrocardiogram, chest Xray, vision testing (acuity-Snellen, color-Ishihara, and peripheral fields), an audiogram, a drug screen, and a psychological evaluation. After reviewing the above information, the medical provider forwards their medical fitness-for-duty determination to the fire department. The engineer completed his preplacement medical evaluation in 1997 and was cleared for full duty as a fire fighter.

The fire department does not require periodic member medical evaluations. However, they do offer a voluntary fitness-wellness program administered by the fire department's wellness coordinator and a local health maintenance organization (HMO). The fitness portion of the program involves a fitness evaluation test administered at the city's fire academy and fitness evaluations/programs tailored to the individual fire fighter by a fire department physical therapist. The wellness portion of the program involves a medical evaluation (Smart Set Physical) performed by the local HMO. The fire department estimates approximately $30 \%$ of its members take advantage of the fitness-wellness program. Other than a fire department medical evaluation in 2000, the engineer did not participate in the fire department fitness-wellness program.

The fire department has written policies and procedures, which are available to all department members within their stations. These policies and procedures have been implemented and are enforced.

\section{Training and Experience}

The fire department follows strict hiring and training policies. At the time of this investigation, all new full-time fire fighter applicants were required to be 19 years of age, be a U.S. citizen upon application, be a resident of the state of Colorado at the time of hire, have a high school diploma or a General Equivalency Diploma (GED) on or before the date of application, have a valid state driver's license, not have any disqualifying legal impediments, and obtain and maintain certification as an Emergency Medical Technician (EMT). The Entry Level Fire Fighter examination process includes an elevenphase process:

Phase 1: Computerized Application

Phase 2: Computerized Written Test

Phase 3: Behavioral Questionnaire

Phase 4: Supplemental Application Form and Background History Form

Phase 5: Candidate Physical Agility Test_-Fire Service Joint Labor Management

Wellness/Fitness Initiative Candidate Physical Ability Test

Phase 6: Written Suitability Assessment

Phase 7: Polygraph Examination

Phase 8: Interview with a Psychologist

Phase 9: Preliminary File Review

Phase 10: Background Investigation

Phase 11: Commission

Upon commission of the entry-level examination process, the successful candidate is placed into a group of potential new hires where they must then complete a candidate medical evaluation described 


\section{Career Fire Fighter/Engineer Dies After Falling Through Translucent Corrugated Roof Panel While Searching for Fire Extension-Colorado}

above. A final offer is then made and the applicant is sent to the department's 17-week fire fighter academy. After successful completion of the academy, the recruit becomes certified through the Colorado Metropolitan Certification Board as a Fire Fighter I. Prior to moving beyond probationary status, the fire fighter must achieve Pro-Board certification at the Fire Fighter II level.

The Truck 8 engineer who was injured in this incident had 15 years of experience as a fire fighter. He received fire service training in a large variety of subjects, including engine company operations, truck company operations, forcible entry, care and maintenance of forcible entry tools, ground ladder training, horizontal ventilation, search and rescue operations, hose lays, rope knots, and cleaning, inspecting, and maintaining personal protective equipment. He had received certification in Firefighter I, Firefighter II, Fire Instructor I, Defensive Driving, Hazardous Materials Operations, ICS 100, ICS 200, ICS 700, and ICS 800.

The Truck 8 lieutenant had 16 years of experience as a fire fighter, including serving the past 8 years as a lieutenant. He had received training in a large variety of subjects, including engine company operations, truck company operations, technical rescue, care and maintenance of forcible entry tools, ground ladder training, vehicle extrication, forcible entry, hose lays, horizontal ventilation, pre-incident surveys, search and rescue operations, rope knots, and career development. He had received certification in Firefighter I, Firefighter II, Fire Instructor I, Hazardous Materials Operations, ICS 100, ICS 200, ICS 700, and ICS 800.

The incident commander had over 34 years of fire service experience, including 29 years with this department. He had been a chief officer for 14 years. He had received training in a large variety of subjects, including division operations, career development, technical rescue, special operations, and truck company operations. He had received certification in ICS 100, ICS 200, ICS 700, ICS 800, Incident Safety Officer, Firefighter I, Fire Instructor I, and Fire Instructor II.

\section{Equipment and Personnel}

This incident was initially dispatched for a report of a multifamily commercial structure fire in the city's warehouse district. Per normal standard operating procedures, the following apparatus and personnel were dispatched on district channel 2:

- Engine 9 with an officer, engineer, technician, and fire fighter

- Engine 3 with an officer, engineer, and two fire fighters

- Engine 10 with an officer and three fire fighters

- Tower 9 with an officer and three technicians

- Truck 4 with an officer, engineer, and two fire fighters

- Truck 8 with an officer, engineer, and two fire fighters; designated RIT per SOP

- Rescue 1 with an officer and three technicians

- HAMER 1 with an officer, engineer, and two technicians

- District Chief 2 (incident commander), responded in department chief's vehicle

- District Chief 4, responded in department chief's vehicle

- Ambulance 55 with two paramedics 
Career Fire Fighter/Engineer Dies After Falling Through Trans/ucent Corrugated Roof Panel While Searching for Fire Extension-Colorado

Additional units dispatched included the following units

- Engine 6 with an officer, engineer, and two fire fighters

- Ambulance 36

\section{Timeline}

An approximate timeline for this incident, summarizing the sentinel events up to the time the Truck 8 engineer was transported to the hospital on June 28, 2015, is listed below. The times are approximate and were obtained by studying the available dispatch channel records, fireground audio, witness statements, run sheets, and fire department records. This timeline is not intended, nor should it be used, as a formal record of events. Only those events directly related to the fall are included.

- 2129:55 Hours

911 phone call reporting "multifamily commercial structure fire” transferred to fire dispatch.

- 2130:59 Hours

Engine 9, Tower 9, Engine 3, Engine 10, Truck 4, Truck 8, District Chief 2, District Chief 4, Rescue 1, and HAMER 1 dispatched. Truck 8 designated as the Rapid Intervention Team (RIT).

- 2133:57 Hours

Tower 9 and Engine 9 arrive on-scene. Tower 9 lieutenant assumes command and reports a dumpster fire outside of a warehouse next to a building. Engine 9 lays out from hydrant to building.

- 2134:40 Hours

Engine 3, Engine 10, Truck 4, and HAMER 1 arrive on-scene. Command directs them to stage.

- 2135:11 Hours

District Chief 2 arrives on-scene and assumes command from the Tower 9 lieutenant. Command assigns Tower 9 to get access into the building to check for fire extension into building. Command assigns Truck 4 to obtain a 360-degree search of the outside of the building.

- 2135:50 Hours

HAMER 1 radios Command that HAMER 1 crew is doing 360-degree search of the building.

- 2136:21 Hours

Tower 9 lieutenant radios Command that fire scorched an exterior wall and the front doors are locked.

Command assigns Tower 9 to force entry into the building.

- 2136:49 Hours

Truck 8 arrives on-scene.

Command assigns Truck 8 to gain access to the roof via a ground ladder and check for fire extension using a thermal imager.

HAMER 1 reports that the rear of the structure is clear.

- 2138:00 Hours 


\section{Career Fire Fighter/Engineer Dies After Falling Through Translucent Corrugated Roof Panel While Searching for Fire Extension-Colorado}

Truck 4 reports that entry was made through a man door on Side Charlie.

Tower 9 reports they made entry by forcing the bay door on Side Alpha.

- 2138:21 Hours

District Chief 4 arrives on-scene and radios Command.

Command tells District Chief 4: "No need to suit up. I think that this is going to be a fire that's under control. I just want to verify there is no extension on the inside.”

- 2138:55 Hours

Ambulance 55 arrives on-scene and is staged.

- 2139:12 Hours

Tower 9 reports: "We are directly on the other side of the wall, where the dumpster was. We're getting slightly elevated heat readings in here, and a little bit showing up on the thermal, but nothing very much."

Command tells Tower 9 to stand by.

Rescue 1 arrives on-scene.

- 2139:49 Hours

Command directs Tower 9 to cut open a small portion of the interior wall adjacent to the dumpster to check for extension.

Truck 4 reports to Command that there is a small amount of smoke on the inside of the building. Command then directs Truck 4 to conduct a primary search of the interior of the building.

- 2140:48 Hours

Command radios Rescue 1 to go back in service.

Command radios Engine 6 and Engine 10 to go pick up then go back in service.

Rescue 1 and Engine 6 acknowledge.

- 2142:17 Hours

Command radios Truck 8 Bravo (Truck 8 engineer) and requests the dimensions of the roof.

- 2142:39 Hours

Truck 8 engineer replies: "I’d say approximately 300 by 60. Appears rectangular except for this little notch you see here where the dumpster was."

Command asks for message to be repeated. Truck 8 engineer repeats dimensions.

Command acknowledges dimensions.

Truck 8 engineer falls through translucent corrugated roof panel into the bay area of the fire building.

Truck 8 lieutenant reports to Command: "No hot spots on the roof... and we have a fire fighter down, Chief. Fire fighter went through the roof.”

Command acknowledges message.

Command asks EMS to proceed from their staged position to the Alpha side of the building to assist the fire fighter.

Fire fighters from several companies and EMS immediately attend to Truck 8 engineer. 


\section{Career Fire Fighter/Engineer Dies After Falling Through Translucent Corrugated Roof Panel While Searching for Fire Extension-Colorado}

District Chief 4 is assigned to direct overall packaging and transport activities of Truck 8 engineer.

- 2143:38 Hours

Tower 9 reports to Command that building is cooling and the fire is out.

District Chief 4 guides Ambulance 55 to the loading dock door on the Alpha side of the building.

Ambulance 36 (requested by Ambulance 55) arrives and is staged.

- 2145:08 Hours

Command asks District Chief 4 if more help is needed.

District Chief 4 reports he has sufficient help and is clearing crews out.

- 2145:36 Hours

Command confirms with Truck 8 lieutenant that all members of Truck 8 are off the roof.

- 2145:56 Hours

Command requests a face-to-face conversation with District Chief 4.

- 2147:06 Hours

Command begins to release crews to go back into service.

Command asks Rescue 1 to complete the primary search of the building to ensure there are no occupants in the building.

- 2150:00 Hours (Approximate)

Truck 8 engineer is loaded into Ambulance 55, which departs for Hospital 1.

- 2230:27 Hours

District Chief 2 terminates incident command and goes back into service.

\section{Personal Protective Equipment}

At the time of the incident, the engineer was wearing his turnout gear (coat and pants), helmet, Nomex ${ }^{\circledR}$ hood, gloves, boots, and a self-contained breathing apparatus (SCBA) with an integrated personal alert safety system (PASS). The victim was also equipped with a portable radio and flashlight. The engineer's turnout gear and equipment was not considered to be a contributing factor in this incident.

\section{Weather and Road Conditions}

On June 28, 2015, at 2142 hours (approximate time of incident), the temperature was 66 degrees Fahrenheit, the humidity was at 59\%, the barometric pressure was 30.60 inches, visibility was 10 miles, the wind was from the south at 9.2 miles per hour, and it was mostly cloudy. A thunderstorm had passed through the area about 2 hours prior to the incident; however, there had been no precipitation in the past 24 hours [Weather Underground 2015].

\section{Structure}

The fire originated in a roll-off dumpster outside of a one-story commercial building in the warehouse district of the city. According to city records, the 16,795-square-foot structure was built in 1970 out of 


\section{Career Fire Fighter/Engineer Dies After Falling Through Translucent Corrugated Roof Panel While Searching for Fire Extension-Colorado}

Type II-B unprotected noncombustible construction (see Photo 1). The building operated as a storage facility and was leased by two separate businesses: one storing electric rickshaws and the other storing household furniture. At the time of the incident and during the NIOSH investigation, the loading dock and bay area were empty. Two large roll-up doors at Side Alpha and two man doors on the Alpha and Charlie sides of the building provided access to the central bay area. The first roll-up door provided access to a covered recessed loading dock. The second roll-up door provided ground-level access to the bay area. The rickshaw storage area was located at the Bravo side of the structure and was separated from the central bay area by an interior wall. An interior, locked chain-link fence separated the bay from the furniture storage area on Side Delta (see Diagram 1). An office space, used by building management, was located adjacent to the bay along the Side Alpha wall. Additional office space in a mezzanine area was located along the Alpha side of the building, next to the furniture storage area.

Outside of the building, the Alpha and Bravo sides of the building were surrounded by concrete parking lots/driveways and the Charlie and Delta sides were surrounded by natural foliage. On the exterior Charlie/Delta corner of the building, a locked chain-link fence had been constructed between the fire building and another furniture storage warehouse. Five additional warehouses were located on Bravo and Charlie sides of the building on the same city block. A paved road and a railyard were located on the Alpha side of the building and a Park N' Ride for the future light rail/train was being built between the railroad tracks and the street (see Photo 1).

The building consisted of two sections that were joined perpendicular to one another to form an "L" shape (see Photo 1, Photo 2, and Diagram 1). The symmetrical, clear-span, rigid-frame building was constructed on a concrete slab foundation. The walls were constructed using corrugated steel sheets. The roof was a gable style with a 2:30 (6\%) pitch (see Photo 3). The main portion of the building was estimated to be approximately 20 feet in height, 300 feet in length, and 60 feet in width. NIOSH investigators and fire department officials measured the point of the fall and determined that the Truck 8 engineer fell 17 feet 4 inches from the broken roof panel to the concrete floor inside the building. 


\section{Career Fire Fighter/Engineer Dies After Falling Through Translucent Corrugated Roof Panel While Searching for Fire Extension-Colorado}

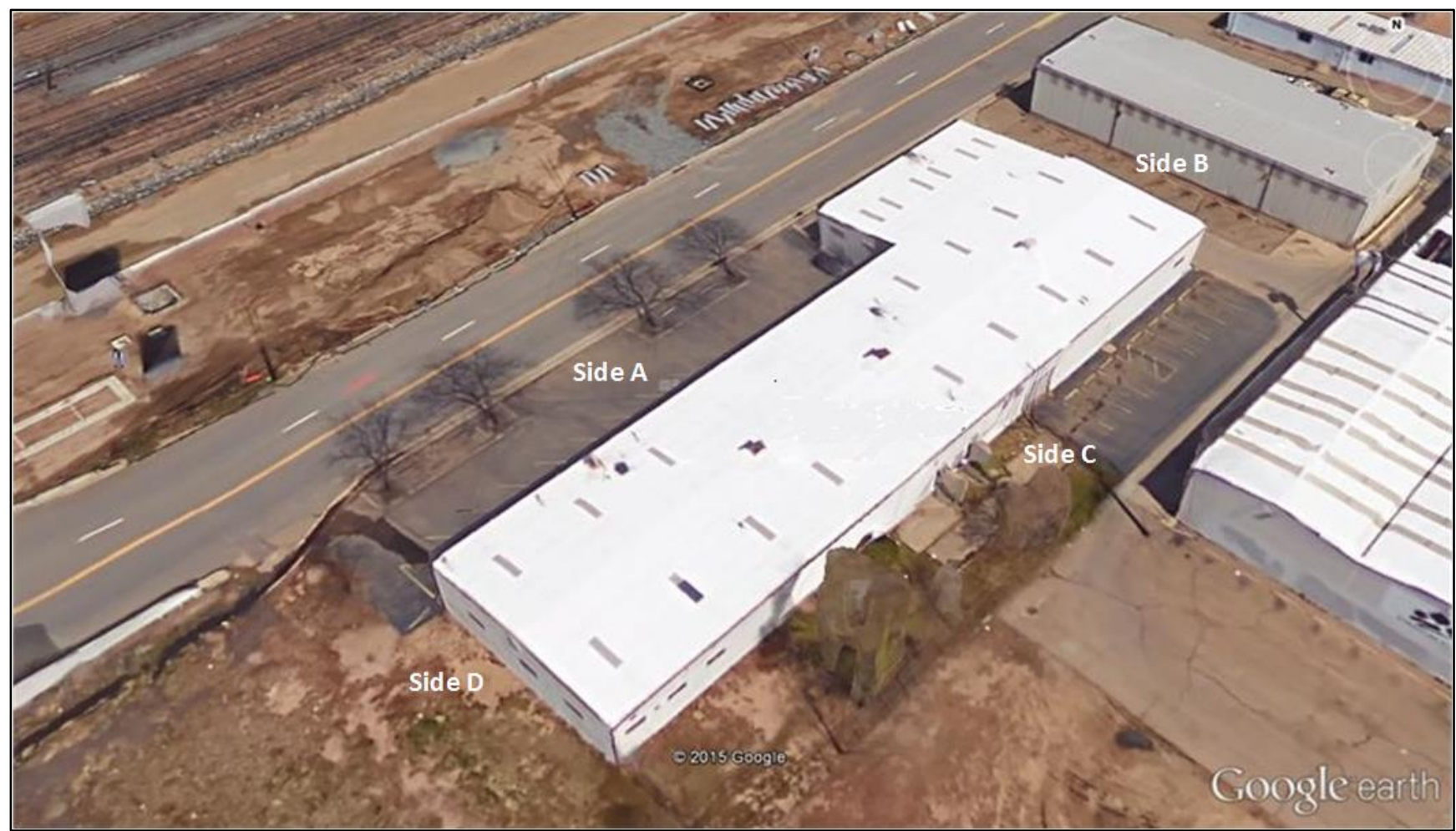

Photo 1. Overhead view of the L-shaped commercial structure. Note that the surrounding buildings also contain translucent corrugated roof panels. This type of structure is common throughout the city where this incident occurred.

(Source: Google Earth.)

The roof of the building was constructed of corrugated steel. Twenty-three translucent corrugated fiberglass roof panels were spread evenly across the roof, except above the mezzanine area. The panels were flush with the corrugated steel roofing panels and had no framing. There were no identifiers or warnings to indicate the presence of the translucent roof panels. The investigators could not determine if the translucent roof panels were installed when the building was built in 1970 or if the building was retrofitted with the panels at a later time. Many of the surrounding buildings in the area had the same rigid frame with corrugated steel and translucent roof panel construction.

The fire department had conducted both prefire planning and fire safety inspections at the incident site. The most recent prefire planning worksheet identified the roof decking material as metal. The worksheet, dated February 23, 2010, did not identify the presence of translucent corrugated roof panels. 
Career Fire Fighter/Engineer Dies After Falling Through Translucent Corrugated Roof Panel While Searching for Fire Extension-Colorado

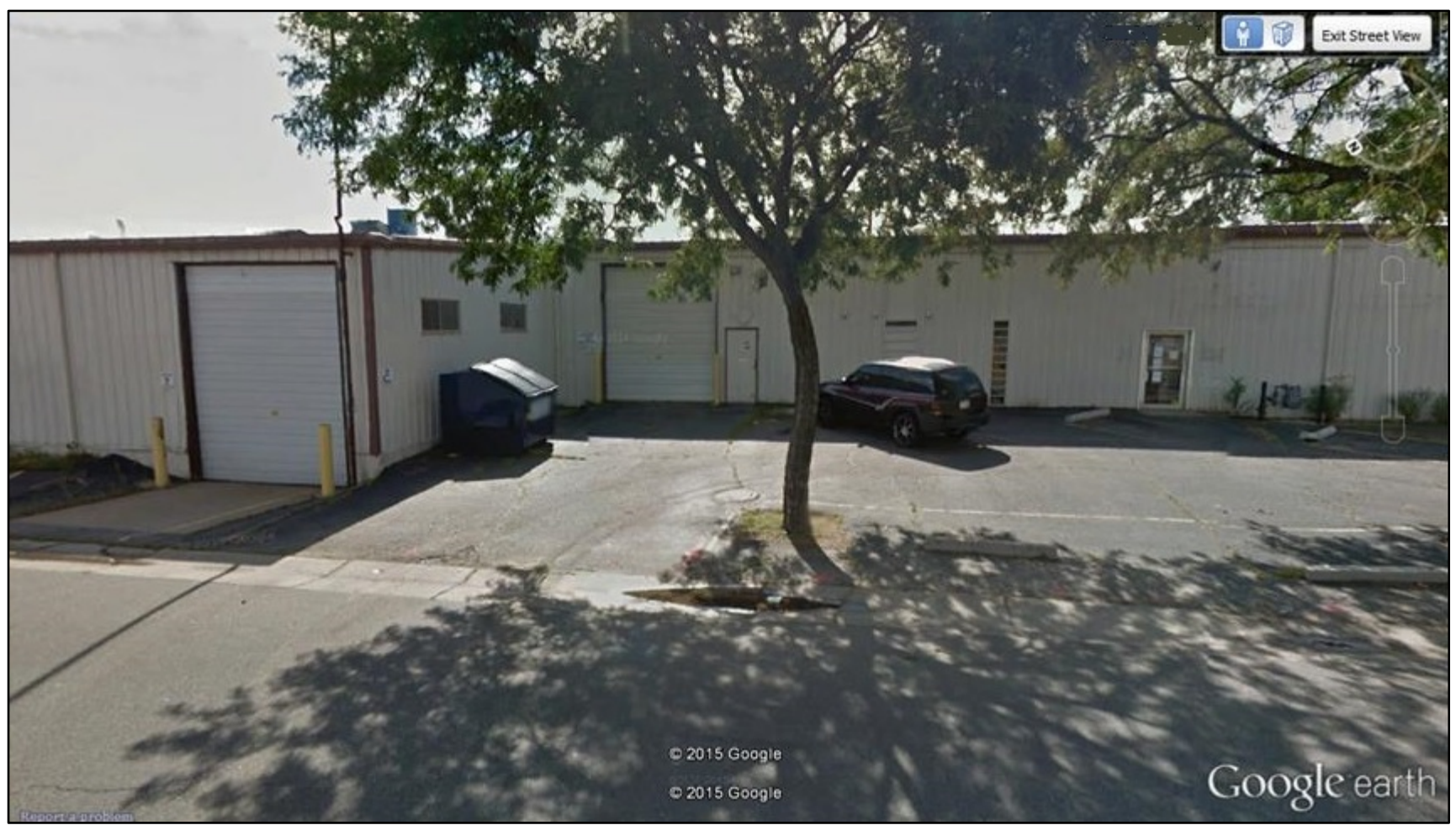

Photo 2. Street-level view of the structure facing Side Alpha. Google Earth photo taken prior to the incident date.

(Source: Google Earth.) 
Career Fire Fighter/Engineer Dies After Falling Through Translucent Corrugated Roof Panel While Searching for Fire Extension-Colorado

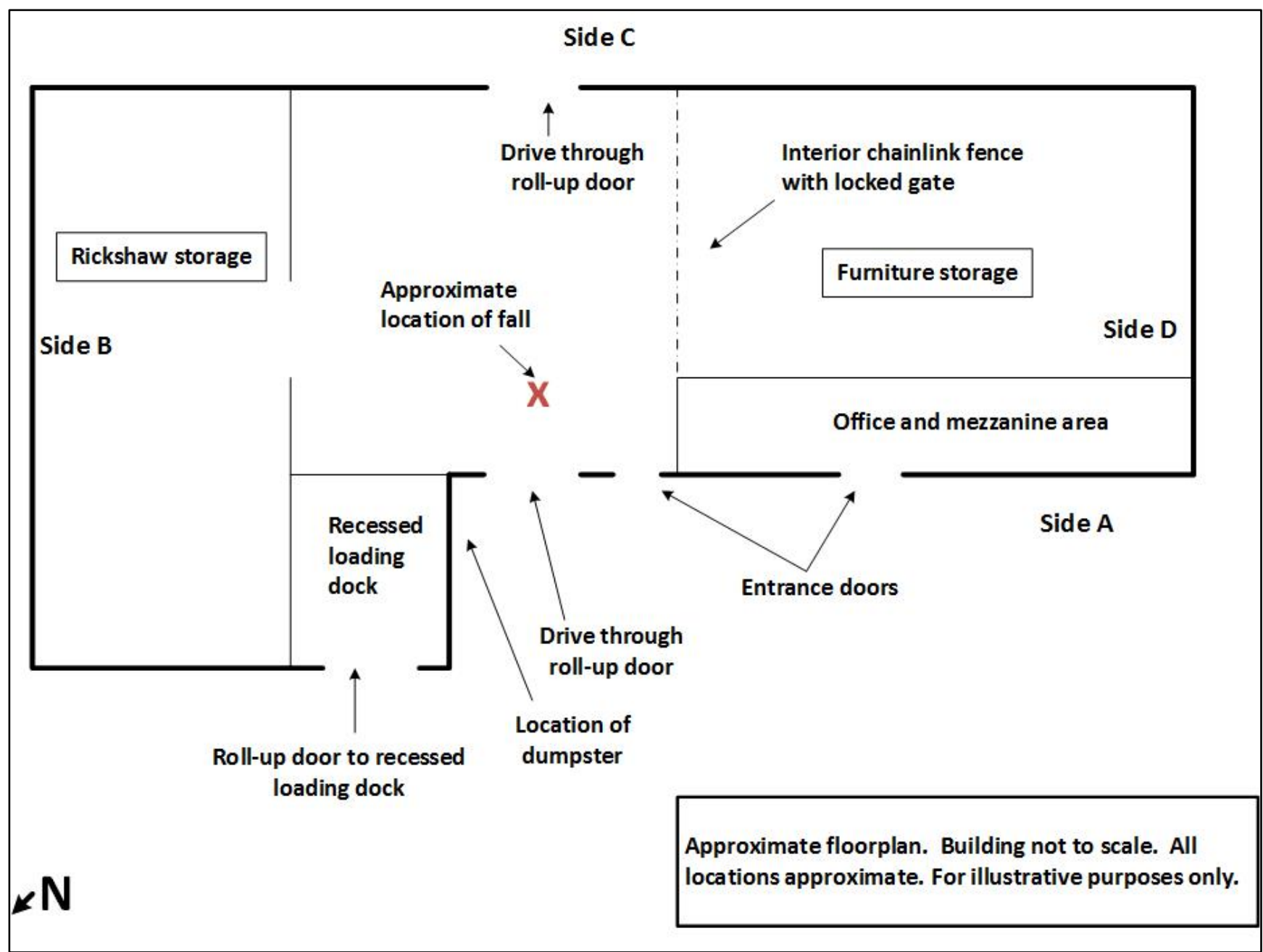

Diagram 1. Approximate floorplan of building interior. (Diagram source: NIOSH.) 


\section{Career Fire Fighter/Engineer Dies After Falling Through Translucent Corrugated Roof Panel While Searching for Fire Extension-Colorado}

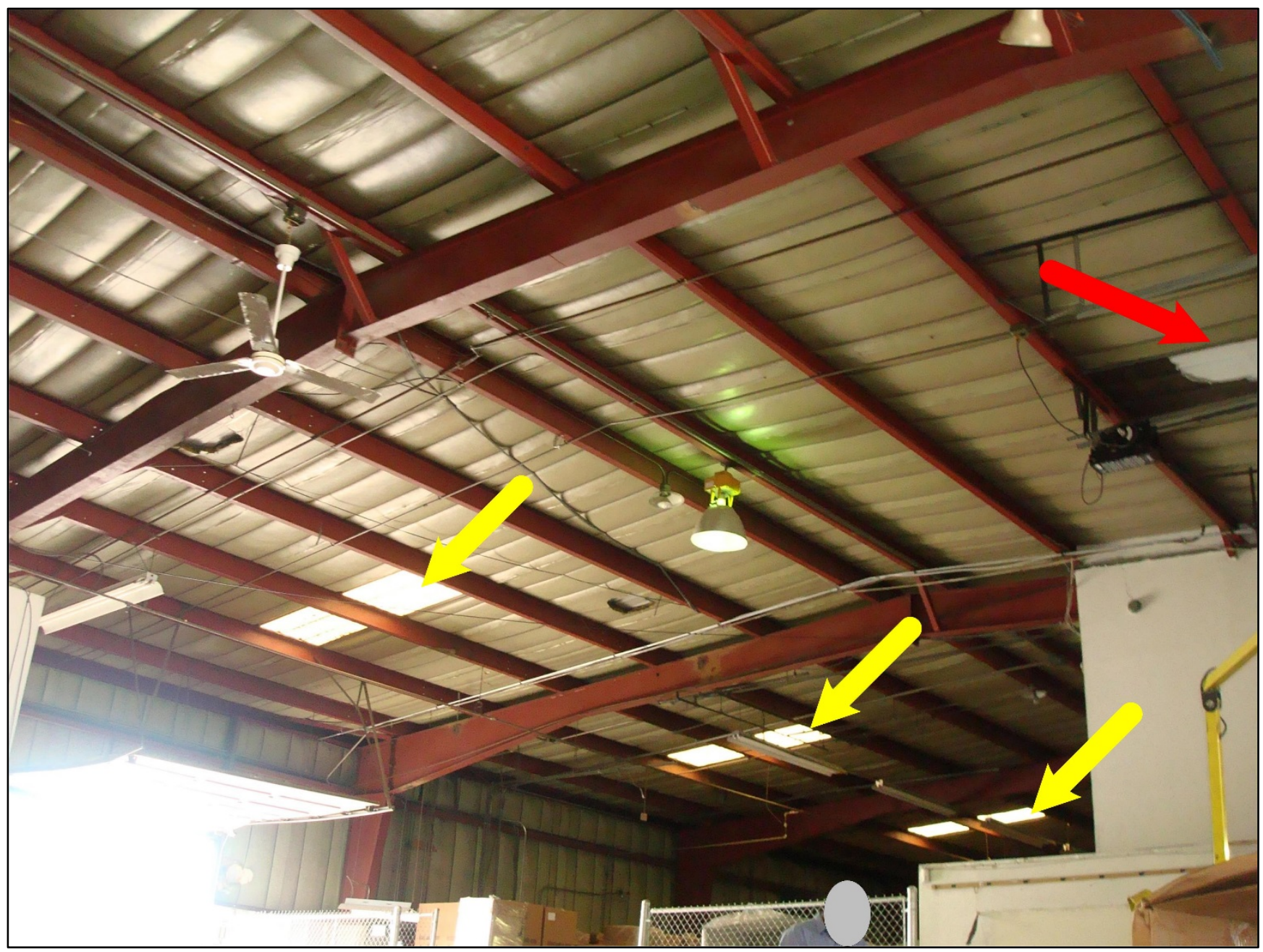

Photo 3. Interior view looking up at roof support system. Note the translucent corrugated roof panels indicated by yellow arrows and the panel where the engineer fell marked by red arrow. The panel that broke has been covered with a sheet of corrugated roof metal.

(Photo source: NIOSH.)

\section{Investigation}

On June 28, 2014, at approximately 21:30 hours, Dispatch received a phone call reporting a possible fire in the warehouse district of the city. At approximately 21:31 hours, three engines, two trucks, one heavy rescue unit, one hazardous materials response unit, two district chiefs, and a third truck company designated as the rapid intervention team (RIT) were dispatched following the department's

established procedures for a commercial structure fire dispatch. Rescue 1, HAMER 1, Engine 9, Tower 9, Engine 3, Engine 10, Truck 4, District Chief 2, District Chief 4, and Truck 8 (as RIT) were dispatched to a "multifamily commercial structure fire" in the warehouse district. Tower 9 and Engine 9 were the first to arrive on-scene and the lieutenant on Tower 9 assumed command and reported: "We have a dumpster outside of a warehouse next to a building. This appears only to be a dumpster." The roll-off dumpster was against Side Alpha of the building, below a window that was in the L-shaped 


\section{Career Fire Fighter/Engineer Dies After Falling Through Translucent Corrugated Roof Panel While Searching for Fire Extension-Colorado}

extension (see Photo 4). The dumpster was estimated to be about 1/3 full of trash of unknown composition burning freely. A technician from Tower 9 used a ceiling hook to pull the dumpster away from the building and the crew from Engine 9 pulled their booster line and quickly extinguished the fire.

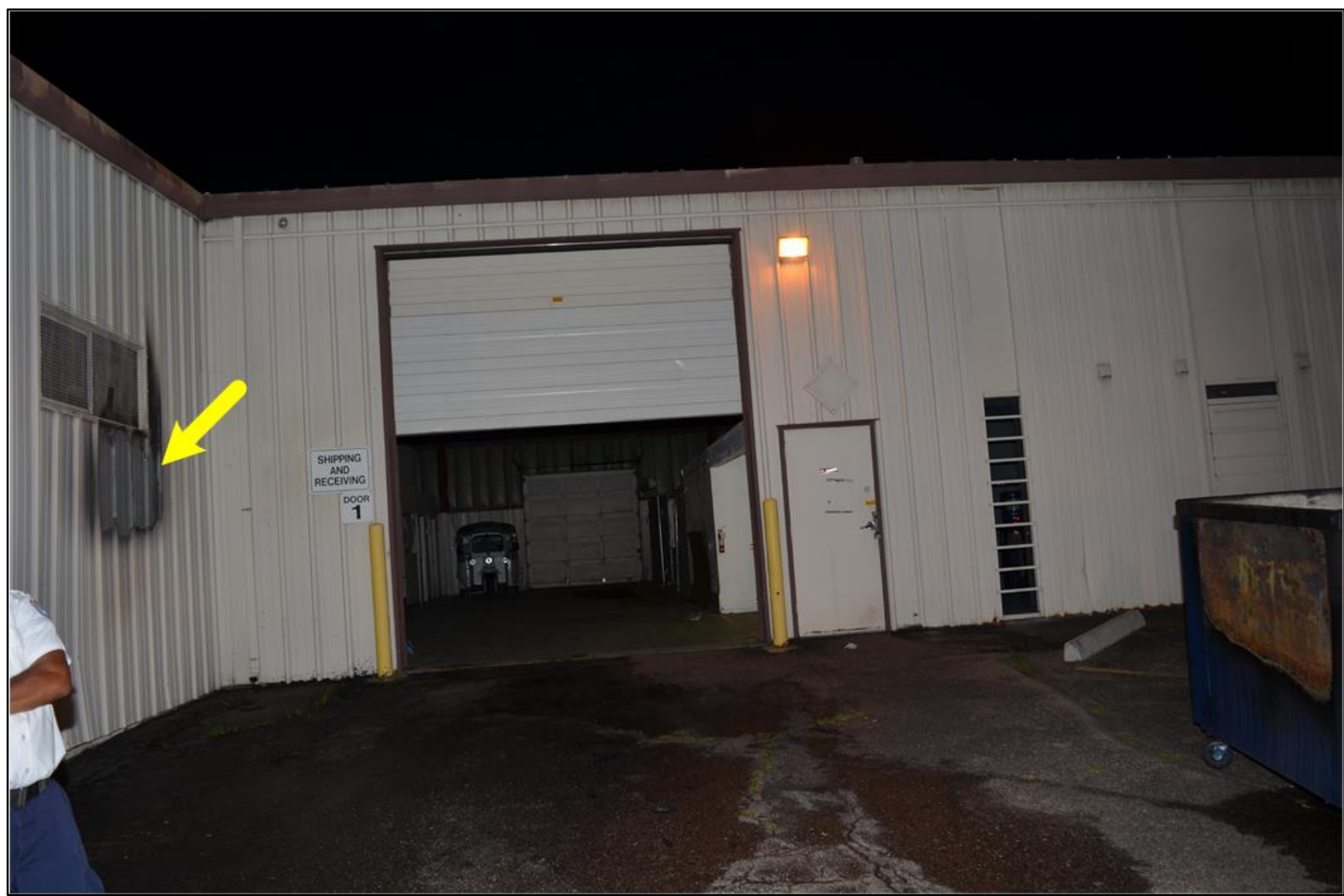

Photo 4. Exterior view of Side A. Yellow arrow at left indicates where the dumpster was located against the exterior wall at the time companies arrived. The dumpster can be seen at the right of the photo. (Photo courtesy of the fire department.)

The Engine 9 engineer laid two 3-inch supply lines that were connected to the nearest fire hydrant. While Tower 9 and Engine 9 suppressed the fire, Engine 3, Engine 10, Truck 4, and HAMER 1 arrived on-scene and were immediately placed in stand-by. There were varying reports from the first fire fighters on-scene regarding the exact height of the flames extending outside of the dumpster along the building exterior, with estimates ranging from 2 to 15 feet. At the time of the NIOSH investigation, a scorch mark, approximately 4 feet high, was visible on the building between the window and the top of the dumpster (see Photo 4 and Photo 5). 


\section{Career Fire Fighter/Engineer Dies After Falling Through Translucent Corrugated Roof Panel While Searching for Fire Extension-Colorado}

Approximately 4 minutes after Tower 9 and Engine 9 arrived on-scene, District Chief 2 arrived and took command from the Tower 9 lieutenant. Since the dumpster had been pulled away from the building and the fire in the dumpster had been extinguished, the response shifted from suppression to checking for fire extension into the building, conducting a 360-degree size-up of the building's exterior, and completing a primary search on the interior of the building. Command assigned Tower 9 to gain access into the building and Truck 4 to complete a 360-degree size-up around the outside of the building. Before Truck 4 could start their search, the HAMER 1 captain reported to Command that two of the HAMER 1 fire fighters were already in the process of conducting a 360-degree size-up.

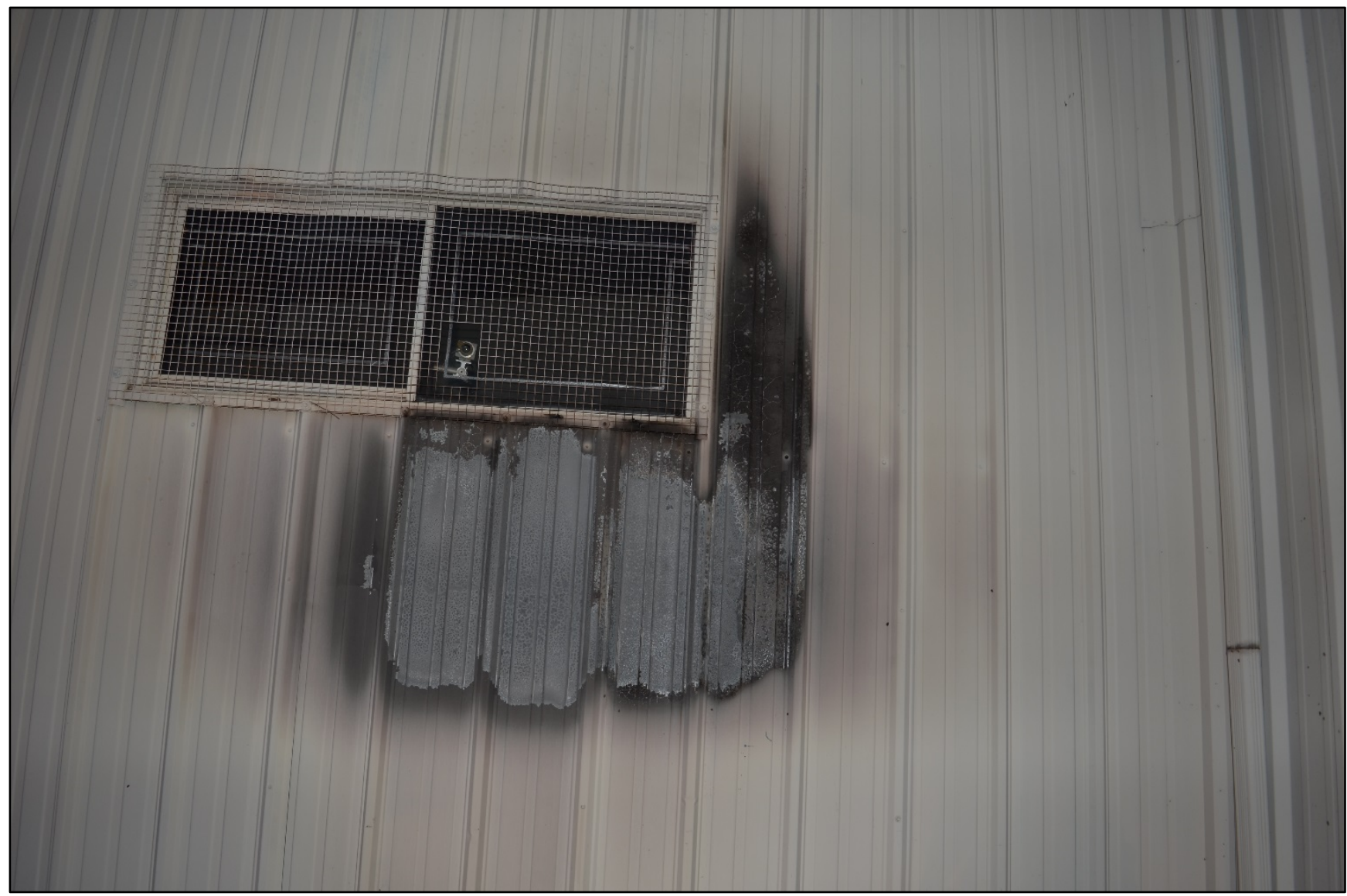

Photo 5. Photo shows extent of fire damage to exterior wall. (Photo courtesy of the fire department.)

While trying to gain entry into the building, Tower 9 reported they were unable to locate a Knox-Box and would need to force a door to get inside. Command instructed the Tower 9 crew to force entry and they were able to pry open a large bay door on the Alpha side of the building. Once inside, the Tower 9 crew proceeded toward the interior side of the wall where the dumpster had been burning, which was located in the recessed loading bay area. Some of the company members reported seeing light, visible smoke in the building at this time. To assess the building for elevated temperatures, they used both a thermal imager and a handheld infrared thermometer. After using their thermal imager, they reported 


\section{Career Fire Fighter/Engineer Dies After Falling Through Translucent Corrugated Roof Panel While Searching for Fire Extension-Colorado}

to Command, "We're getting slightly elevated heat readings in here, and a little bit showing up on the thermal but, nothing very much.” Command then asked them to cut a section out of the interior wall near where the dumpster had been located to verify the fire had not extended into the insulation or other sections of the building. After cutting a 2-foot by 2-foot hole in the wall and finding no extension they started to walk back toward the center bay area.

The Truck 4 crew started their 360-degree exterior size-up, walking from Side Alpha around Side Delta to Side Charlie. The Truck 4 crew encountered a fence with a locked gate at the Charlie/Delta corner of the building, so they walked back around the building, past Side Alpha to Side Bravo to complete the search. When they reached Side Charlie, they located a man door and forced entry into the building. Upon entering the building, they reported to Command, "There's a little smoke over here," and started to look for way to clear out the smoke. They noted overhead fans already in use in the building. Command asked Truck 4 to complete a primary search of the interior to ensure the building did not have any occupants, and the crew began to search the building. The crew was able to search most of the building, however a fence with a locked gate prevented the Truck 4 crew from accessing the Bravo and Delta sections of the building. While searching, the crew opened windows and started to look for ways to access the fenced-off sections of the building.

The HAMER 1 crew also began to complete a 360-degree size-up of the building by splitting into two teams of two, starting at the Alpha side of the building. The same fence that blocked Truck 4 from completing their search also prevented both HAMER 1 teams from fully circling the building and meeting on Side Charlie. During their search, at least two members of HAMER 1 met up with the Truck 4 company at the Side Charlie man door. They reported looking inside the building and seeing a light haze.

While Tower 9, Truck 4, and HAMER 1 were carrying out their assignments, Truck 8 arrived on-scene followed by District Chief 4, Rescue 1, and Ambulance 55. Command assigned Truck 8 to use a ground ladder to access the roof and check for extension using a thermal imager, placed Rescue 1 in service on-scene, and released Engine 6 and Engine 10 (although Engine 6 and Engine 10 did not immediately leave the scene). The senior fire fighter on Truck 8 placed a 28-foot ladder to the right of the man door and roll-up door on Side Alpha (see Photo 6). He then proceeded up the ladder, sounded the roof with his hook, stepped onto the roof, and reported to his crew members that the roof was of metal construction and was sound. The junior fire fighter and Truck 8 lieutenant then proceeded up the ladder, sounded the roof, and joined the senior fire fighter. While on the roof, the senior fire fighter reported he visually inspected the roof with his flashlight and after not identifying any obvious hazards, he turned off the light. After donning his gear, the Truck 8 engineer joined his crew on the roof, briefly sounding the roof after climbing off the ladder. Note: The engineer is the last member of his company to assemble at the scene after donning his turnout gear since he could not drive the truck in full gear. The junior and senior fire fighters started to look for extension immediately above the area where the dumpster was located by walking along the perimeter of the roof. As they proceeded, the junior fire fighter sounded the roof while the senior fire fighter used the thermal imager to search for heat. Once they reached the area of the roof above the dumpster, they reported not seeing any signs of fire extension on the thermal imager and began to walk back toward the ladder. The lieutenant reported he started to follow the junior and senior fire fighters for a short distance; however, he stopped when 


\section{Career Fire Fighter/Engineer Dies After Falling Through Translucent Corrugated Roof Panel While Searching for Fire Extension-Colorado}

Command asked the Truck 8 engineer for the dimensions of the building. To obtain the roof dimensions, the engineer walked toward the peak of the slightly pitched roof to gain the best vantage point. The Truck 8 lieutenant followed and reported stopping about 5 feet from the peak. The lieutenant and engineer discussed the dimensions of the roof before the engineer reported to Command over the radio, "I'd say approximately 300 x 60 and, pretty much rectangular except for the little notch here where the dumpster was.” Immediately after the engineer reported the dimensions, the lieutenant turned away from the engineer and radioed to Command that elevated temperatures had not been detected on the roof using the thermal imager (by the junior and senior fire fighters). The lieutenant was in the middle of making this report when the Truck 8 engineer, after taking one step toward the ladder, fell through the roof. Dispatch records indicated the lieutenant stated, "No hot spots on the roof... and we have a fire fighter down, Chief. Fire fighter went through the roof.”

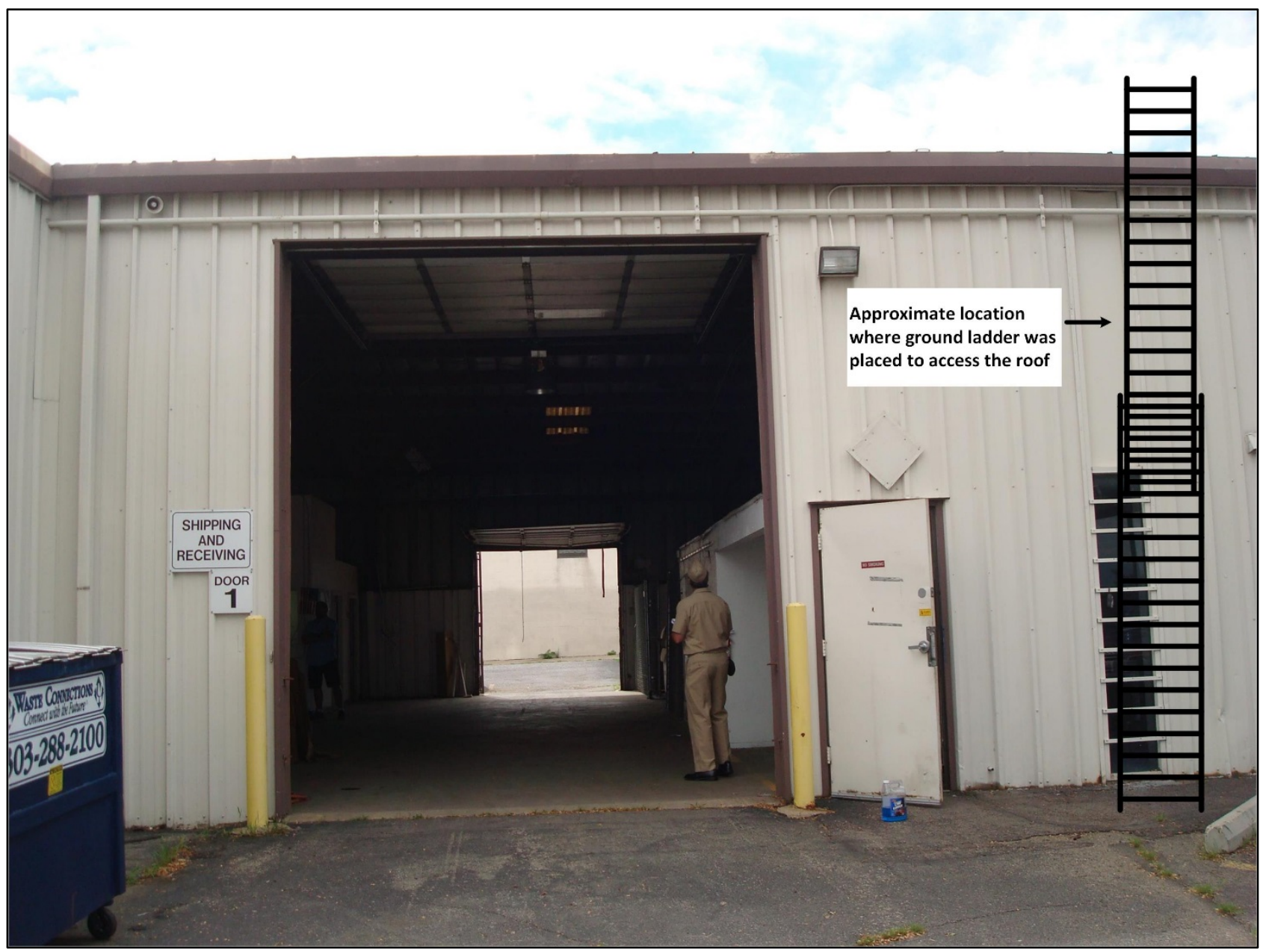

Photo 6. Approximate location where ground ladder was placed to access roof. (Photo source: NIOSH.)

After seeing the engineer fall through the roof, the Truck 8 junior fire fighter immediately began to crawl toward the hole in the roof to see if the engineer had been caught in the roof support structure 


\section{Career Fire Fighter/Engineer Dies After Falling Through Translucent Corrugated Roof Panel While Searching for Fire Extension-Colorado}

and could be reached. The senior fire fighter, recognizing the potential for another fire fighter to fall through roof, grabbed the junior fire fighter and pulled him back away from the hole. The three remaining members of Truck 8 proceeded to exit the roof via the ladder, while the junior fire fighter from Engine 10 secured it from the ground.

The engineer fell approximately 17 feet 4 inches from the roof to the cement floor below (see Photo 3, Photo 7, and Diagram 1). The roof was constructed of corrugated metal with 23 intermittently spaced translucent corrugated roof panels (see Photo 1). The engineer fell through the translucent corrugated roof panel, and tried to break his fall with his right arm. Members from Tower 9, Truck 4, Truck 8, and District Chief 4 all reported either hearing or seeing something fall through the roof, but it was not immediately clear that a fire fighter had fallen. Many fire fighters also reported not being unable to see the hole in the translucent corrugated roof panel because it blended in with the roof, especially in the low-light conditions at night (see Photo 7 and Photo 8).

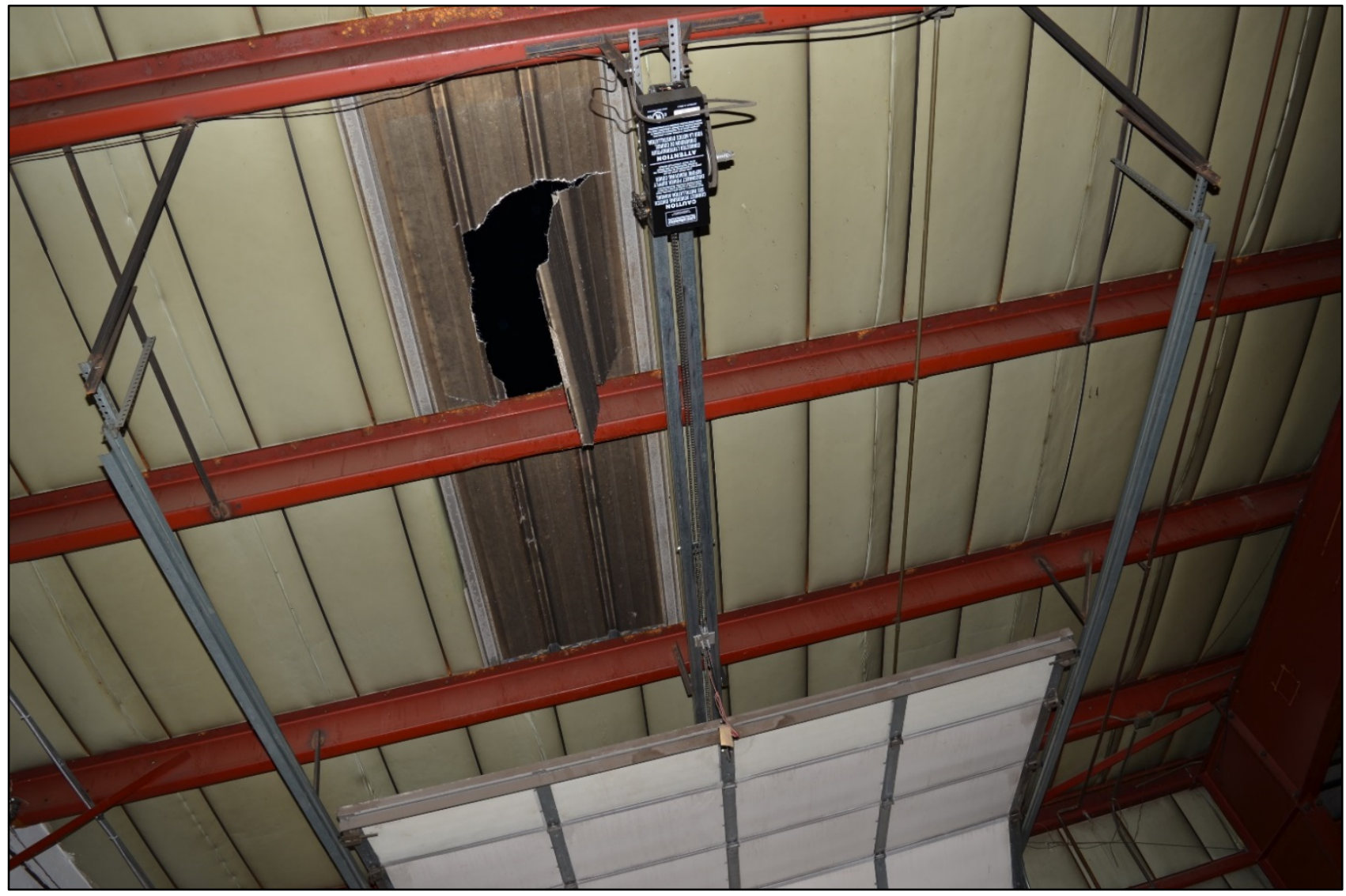

Photo 7. Interior view looking up at the translucent corrugated roof panel where the engineer fell. Photo taken the night of the incident.

(Photo courtesy of the fire department.) 


\section{Career Fire Fighter/Engineer Dies After Falling Through Translucent Corrugated Roof Panel While Searching for Fire Extension-Colorado}

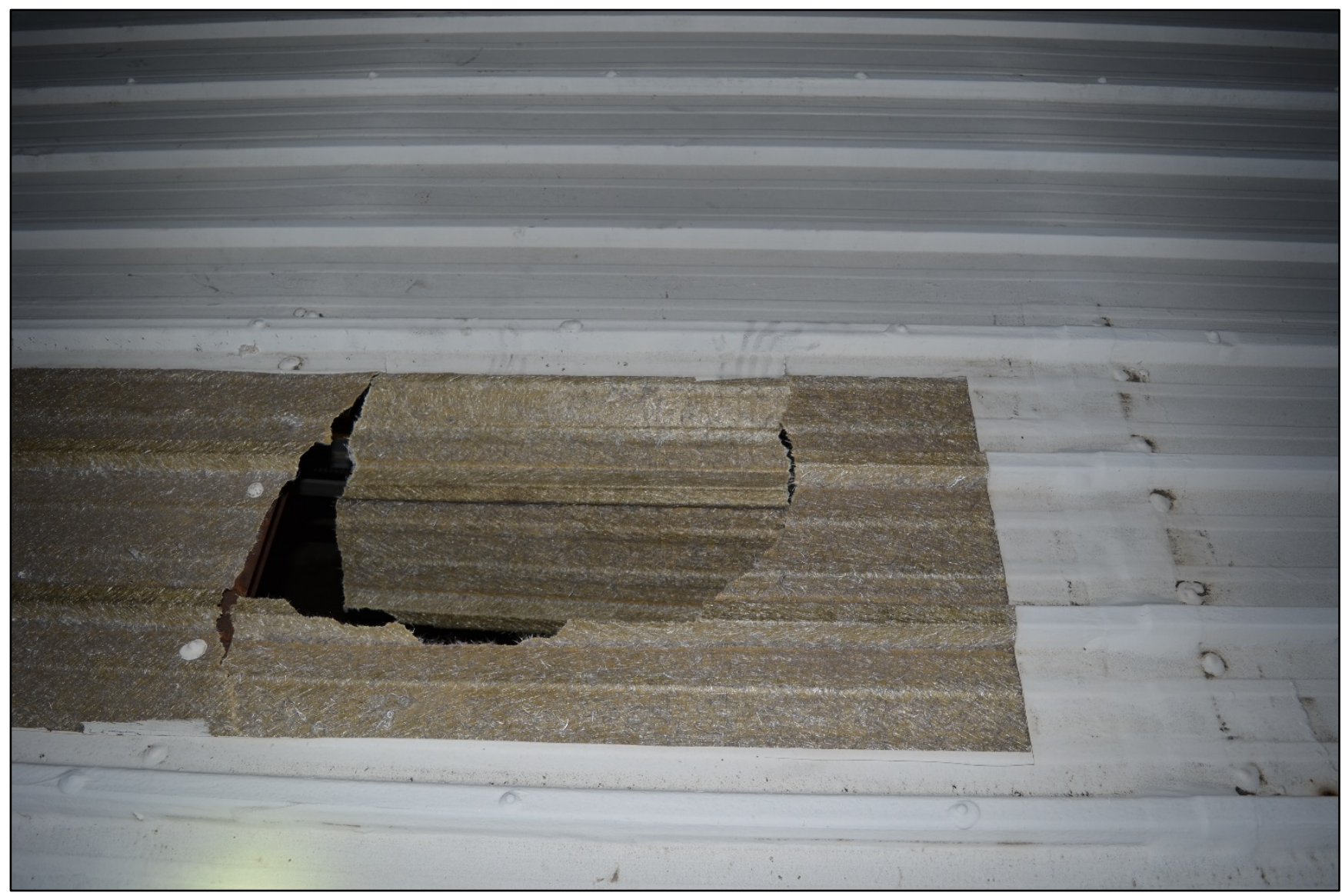

Photo 8. Close-up of translucent corrugated roof panel taken from the roof on the night of the incident. Note how the translucent corrugated roof panel lacks a frame or other indicator of its presence, allowing it to blend with the rest of the roof. (Photo courtesy of the fire department.)

Immediately after the fall, several fire fighters ran to aid the engineer. Company members from Truck 4, Tower 9, Engine 9, and HAMER 1 were the first to reach the injured engineer. Fire fighters worked to provide emergency first aid to the engineer that included providing c-spine support while his SCBA, boots, and pants were removed. Immediately after the fall, Command assigned District Chief 4 to coordinate the activities inside the building. To ensure fire fighter safety, District Chief 4 confirmed that all fire fighters were off the roof. The on-scene paramedics were notified of the incident and asked to bring a stretcher to the structure. It was reported that the engineer was awake, was attempting to stand up, and had commented multiple times that he was having difficulties breathing. The engineer's right arm was twisted into an unnatural position and was bleeding profusely.

Suspecting that the engineer could have severe internal injuries, fire fighters removed his bunker gear, moved his arm out from under him, and cut the engineer's sleeve. It was reported that the trauma shears used by the department couldn't cut through the bunker gear and fire fighters had to use a knife 


\section{Career Fire Fighter/Engineer Dies After Falling Through Translucent Corrugated Roof Panel While Searching for Fire Extension-Colorado}

to cut the gear off. When the paramedics arrived, they checked the engineer's airway, reported it was clear, and then moved him to Ambulance 55 where he was transported to Hospital 1.

Because the area immediately around the engineer quickly became congested, the crews who were not directly attending to the Truck 8 engineer were assigned to return to their apparatus, finish conducting a primary search, or move hoses and engage in work on the periphery.

The engineer suffered open fractures of the bones in his forearm (distal radius and distal ulna), an open elbow dislocation, severing of his right brachial artery, multiple right-sided rib fractures (ribs 2 thru 8), and fractures of the transverse processes of the lumber spine (L2-4). After he was taken to the emergency department, he was taken to the operating room where he underwent closed reduction and external fixation of his right elbow, closed reduction and repair of his right wrist, vascular repair of his severed right brachial artery with a reverse saphenous vein interposition graft from his right thigh, right arm fasciotomy, and a skin graft of the right forearm fasciotomy from his left thigh. Throughout his 11-day hospital course he was anticoagulated with intravenous heparin to prevent thrombus formation, which was switched to Lovenox ${ }^{\circledR}$ (a low molecular weight heparin) (40 milligrams subcutaneously twice a day), and upon his discharge, an antiplatelet agent (aspirin, 325 milligrams per day).

After release from Hospital 1, the engineer was recovering at home for 6 days when he had the sudden onset of difficulty breathing while walking to his front porch to say goodbye to a visitor. The visitor immediately called 911 (1934 hours) and an ambulance arrived on-scene at 1940 hours. The paramedic found the engineer in moderate respiratory distress with a pulse of 116 beats per minute (normal 60100); rapid, shallow, and labored breaths of 28 per minute (normal 6-12); and a pulse oximetry of 74\% (normal $>95 \%$ ). The engineer told the ambulance crew that he thought he was having a pulmonary embolus (PE). This information was called into the emergency department at Hospital 2 as oxygen was administered via nonrebreather mask, and the ambulance departed for Hospital 2 at 1947 hours. At 1948 hours an intravenous (IV) line was started, and at 1950 hours a cardiac monitor showed sinus tachycardia with no ectopy or changes, suggesting a heart attack. As the ambulance pulled into the emergency department parking lot (1950 hours), the engineer went into cardiac and respiratory arrest, and cardiopulmonary resuscitation (CPR) was initiated.

Inside the emergency department, the engineer was pulseless, apneic, with an oxygen saturation of $50 \%$ (1952 hours). He was intubated with proper tube placement, assessed by direct visualization of the endotracheal (ET) tube passing through the vocal cords, misting on the ET tube, bilateral breath sounds, and color change of the end tidal $\mathrm{CO}_{2}$ detector. His heart rhythm was pulseless electrical activity and resuscitation IV medications were administered. A chest X-ray showed no pneumothorax, and the emergency department physicians agreed that a PE was the likely diagnosis. An IV bolus of tissue plasminogen activator was given at 2009 hours, followed by a second dose at 2018 hours while CPR continued. An echocardiogram was performed at 2014 hours, showing no cardiac activity and no pericardial fluid. After 40 minutes of CPR without any signs of possible recovery, the attending physician pronounced the engineer dead at 2030 hours and resuscitation efforts were discontinued.

The autopsy was performed by a forensic pathology fellow and the assistant medical examiner at the county's Office of the Medical Examiner. Key findings included large pulmonary embolus in both the 


\section{Career Fire Fighter/Engineer Dies After Falling Through Translucent Corrugated Roof Panel While Searching for Fire Extension-Colorado}

left and right lungs and bilateral deep vein thrombi in the anterior and posterior tibial veins (see Appendix 1). In the opinion of the medical examiner's office, the engineer "died as a result of complications [pulmonary embolus] of the blunt force injuries to the right upper extremity and trunk."

\section{Lighting and Visibility on the Roof}

It was reported that when the engine companies arrived at the fire building, it was dark outside (time approximately 2134 hours). Upon arrival, Engine 9 turned on their spotlights, elevating them approximately 12 feet off the ground. Many fire fighters reported that the lighting was poor to adequate, indicating the primary sources of light outside of the building were from surrounding streetlights and lights from the emergency response personnel. Because it was after typical working hours, it was also reported that most of the lights inside the building were off as well. Fire fighters reported that at night while standing on the roof, it was very difficult to differentiate the translucent roof panels from the corrugated sheet metal roof. NIOSH investigators examined the roof and confirmed this finding during their site visit (see Photo 9 and Photo 10). The translucent roof panels were flush with the roof and lacked any identifiers, aside from a slight color difference visible only during daylight hours. The fire department reported that a few days after this incident, images taken using a thermal imager at approximately 2200 hours showed a distinct heat difference between the roof material and the panels. However, whether a heat difference between the panel and the roof material could have been seen in the evening/early morning hours, or in winter months, is unclear.

\section{Hazard Awareness}

During the investigation, many fire fighters reported that while on-scene they did not immediately know the Truck 8 engineer had fallen through a translucent corrugated roof panel; rather they thought he fell through a weak spot in the roof. Many fire fighters reported, after the fall, even on the inside of the building, on first glance the translucent roof panels blended in with the rest of the roof. It was reported, only after careful observation, that they could see the translucent roof panels. While interviewing the different crews involved in this incident, all of the fire fighters reported they had been on a similar roof at least once. It was also reported many fire fighters had been on corrugated sheet metal roofs with these types of translucent roof panels; however, aside from walking around them while on the roof, many fire fighters stated they did not pay much attention to the translucent corrugated roof panels. During this investigation, it was reported to NIOSH investigators that a nearmiss event involving similar circumstances had occurred at this department in 2012. A fire fighter partially fell through a translucent corrugated fiberglass roof panel but was able to catch himself on the roof decking and was uninjured. The 2012 incident was reported through the National Fire Incident Reporting System but the opportunity to use the incident as a source of training and hazard awareness recognition was not effectively reported. 


\section{Career Fire Fighter/Engineer Dies After Falling Through Translucent} Corrugated Roof Panel While Searching for Fire Extension-Colorado

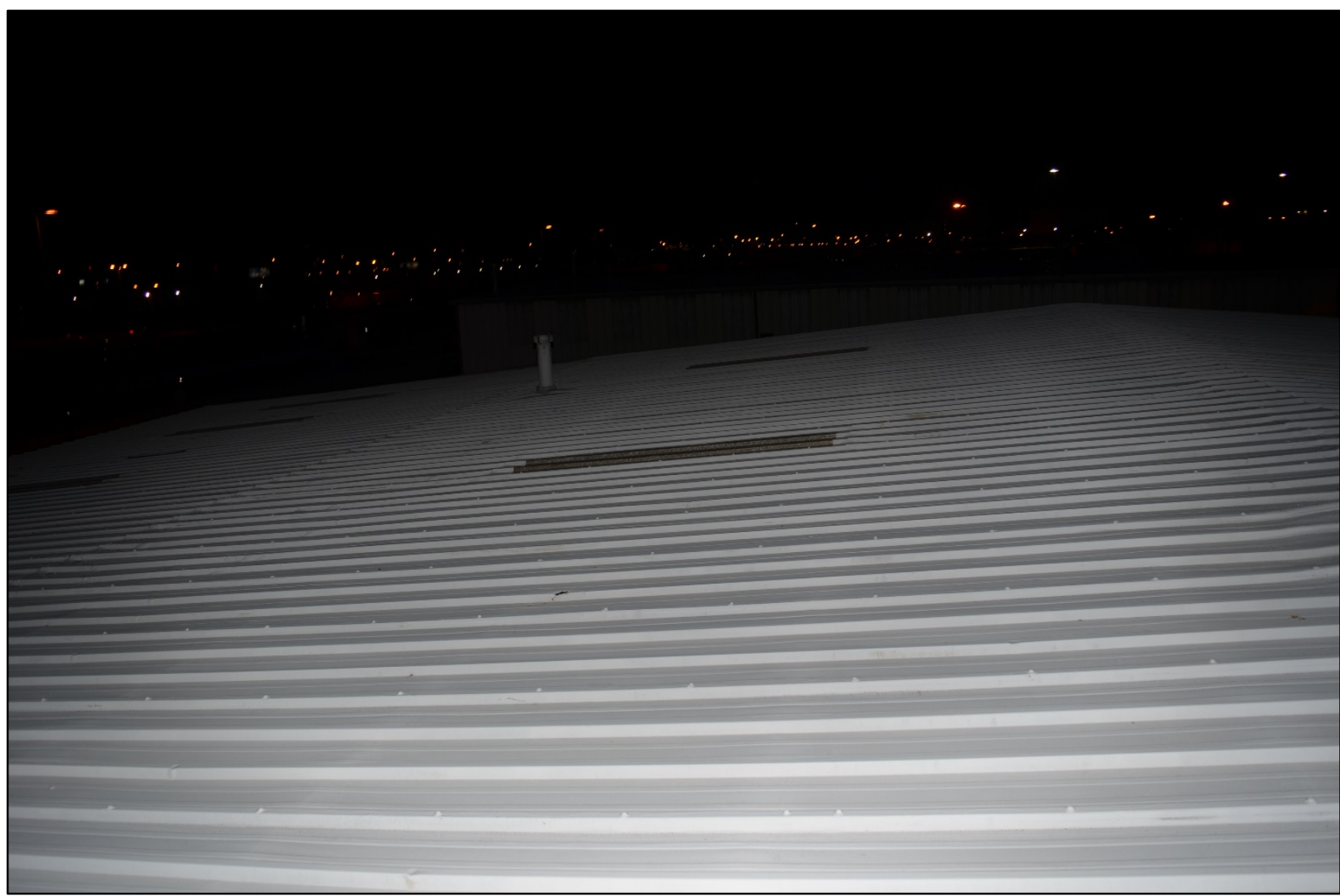

Photo 9. Photo of roof taken during NIOSH investigation at approximately the same time that the incident occurred. In this photo, the roof is illuminated by lights on the fire department's tower ladder.

(Photo source: NIOSH.) 


\section{Career Fire Fighter/Engineer Dies After Falling Through Translucent Corrugated Roof Panel While Searching for Fire Extension-Colorado}

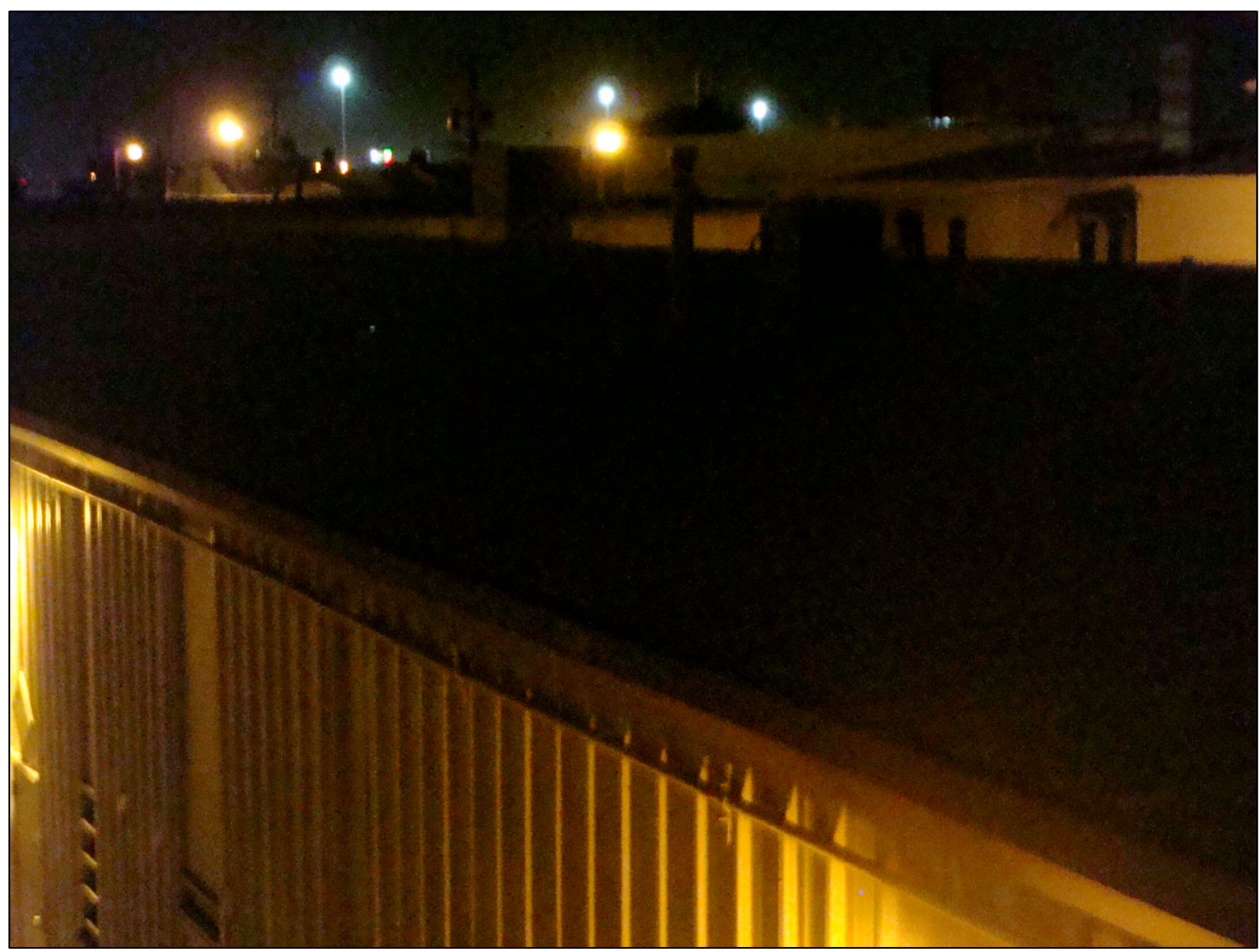

Photo 10. Photo taken of the structure's roof during NIOSH investigation at approximately the same time in the evening that the fall occurred. Note that under low-light conditions, the translucent corrugated roof panels are indistinguishable from the surrounding sheet metal roof. (NIOSH photo.)

\section{Contributing Factors}

Occupational injuries and fatalities are often the result of one or more contributing factors or key events in a larger sequence of events that ultimately result in the injury or fatality. NIOSH investigators identified the following items as key contributing factors in this incident that ultimately led to the fatality:

- Unrecognized fall hazard associated with walking on translucent corrugated roof panels.

- Low light conditions on the roof.

- Engineer distracted by talking on the radio while walking on the roof.

- Roof crew did not continuously sound the roof.

- Previous near-miss incident not effectively reported as a learning tool. 


\section{Career Fire Fighter/Engineer Dies After Falling Through Translucent Corrugated Roof Panel While Searching for Fire Extension-Colorado}

- Translucent roof panels do not require the same load bearing or fall resistance performances in the International Building Codes as scuttles or skylights.

- Translucent roof panels, skylights, or scuttles may not be identifiable from roof panels.

\section{Cause of Death}

According to the medical examiner's office report, the Truck 8 engineer “died as a result of a massive pulmonary thromboembolism from lower extremity thrombus formed as a result of blunt trauma injuries from a fall on June 28, 2015.”

\section{Recommendations}

Recommendation \#1: Fire departments should ensure that all fire fighters, company officers, and chief officers are aware of and trained to recognize translucent corrugated roof panels and the fall hazard these panels present.

Discussion: Translucent corrugated panels are designed to transfer natural light and heat into a building's interior. Translucent corrugated panels are typically used in sheet metal roof and wall structures. These panels may or may not be easily recognizable and in some cases may be painted or tinted to blend in with the existing roof. These panels are designed in a variety of shapes, sizes, and colors and may be difficult to recognize, especially at night. These panels have different strength and material properties than sheet metal and are typically not designed to be stepped or walked upon, will not support the weight of a fire fighter (with or without personal protective equipment and tools), and may degrade when exposed to UV, water, and other chemicals. These roof panels can be found in a variety of buildings, including manufacturing facilities, warehouses, storage buildings, restaurants, carports, canopies, barns, and covered walkways in both commercial and residential settings. While translucent corrugated panels are commonly referred to as sky lights, traditional sky lights typically incorporate a raised frame or structure around the opening. This frame makes the traditional sky light much easier to detect, both by sight and by feel, when darkness or smoke limits visibility.

In this incident, the Class 2, noncombustible structure contained a number of translucent corrugated roof panels. This incident occurred at 2142 hours as night was falling. Low light conditions limited the ability to distinguish between the roof deck and the translucent corrugated roof panels. The roof crew and, in particular, the Truck 8 engineer were preoccupied with reporting the dimensions over the radio to Command. The Truck 8 engineer probably did not realize he was walking on a translucent corrugated roof panel that broke under his weight. During this investigation, it was reported to NIOSH investigators that a near-miss event involving similar circumstances had occurred at this department in 2012. A fire fighter partially fell through a translucent corrugated fiberglass roof panel but was able to catch himself on the roof decking and was uninjured. The 2012 incident was reported through the National Fire Incident Reporting System, but the opportunity to use the incident as a source of training and hazard awareness recognition was not effectively reported. 


\section{Career Fire Fighter/Engineer Dies After Falling Through Translucent Corrugated Roof Panel While Searching for Fire Extension-Colorado}

Recommendation \#2: Fire departments should establish policies and procedures to ensure that fire fighters follow safe roof operating practices, including sounding the roof; not walking or standing on translucent corrugated roof panels, scuttles, and skylights; using flashlights or external lighting in low-light conditions; having enough ladders for safe exit; and always wearing the proper personal protective equipment, including self-contained breathing apparatus.

Discussion: In order to safely operate on a roof, fire fighters need to know and understand the basic types and designs of roofs and how the roofs in their response areas are constructed. Reference books such as Essentials of Fire Fighting and Fire Department Operations [IFSTA 2008] and Building Construction Related to the Fire Service [IFSTA 2010] contain valuable information for the fire service related to roof construction, design, materials, and safety issues. Both books mention skylights but do not mention translucent corrugated roof panels. Fire departments need to ensure that standard operating procedures and/or guidelines are established that cover safe work practices and procedures while working on roofs and elevated surfaces, and include the potential hazards of translucent roof panels.

Crews operating on roofs should be equipped with portable radios so that they can stay in constant contact with supervisors and incident command. Whenever possible, two separate means of egress from the roof should be established. This can be two separate ground ladders at separate locations, two aerial ladders or aerial platforms, or combinations of ground ladders and aerial devices. Extend the rungs of ground ladders at least three to five rungs above the roof line and secure the ladder. Check the roof for structural integrity by both visual observation and sounding the roof before stepping onto it. Continue sounding the roof throughout the operation. Whenever possible, walk over or near bearing walls and the strongest points of the roof structure. Be aware of the warning signs of a weakened roof such as melting asphalt, smoke or fire coming through the roof, and a "spongy" roof (one that appears solid but feels soft or springs back when walked upon) [IFSTA 2008]. Note: Some roofs can be spongy without any fire involvement, such as roofs that have been deteriorated by rotting wood, insects, and renovation work. Fire fighters should also use flashlights or external lighting throughout roof operations in low-light conditions. Operations above grade always increase the risk to operating fire fighters. The use of a flashlight or external light sources may permit fire fighters on a roof to identify the presence of skylights, scuttles, or translucent corrugated roof panels.

The book Essentials of Fire Fighting and Fire Department Operations defines sounding a roof as striking the roof with the blunt end of a pike pole, rubbish hook, axe, or similar tool. A safe roof should provide evidence of both solid feel and sound when struck. The roof should feel solid when struck over support members and may feel less solid when struck between support members. As noted above, the fire fighter should walk on support members whenever possible. The roof may also sound solid when struck over a joist or rafter and produce a more hollow sound when struck between the supports. By practicing on structurally sound roof structures, the fire fighter can learn to recognize the difference in the feel and sound of supported and unsupported areas of a roof. Remember, however, that roofs with several layers of composition shingles or other roof coverings may not respond to sounding as just described. They may sound quite solid when struck with the tool even though the roof supports may have been severely damaged by the fire. Also, roofs covered with tile or slate cannot be sounded; the tiles/slate must be removed to reveal the underlying structure [IFSTA 2008]. Sounding the roof is especially important in cases where low-light, smoke, or fire conditions reduce visibility. It is also 


\section{Career Fire Fighter/Engineer Dies After Falling Through Translucent Corrugated Roof Panel While Searching for Fire Extension-Colorado}

important to note that when sounding a roof, fire fighters should wear a complete ensemble of personal protective clothing and equipment, including gloves, hood, helmet, and self-contained breathing apparatus.

Translucent corrugated roof panels, scuttles, and skylights should not be walked across or stepped upon. Fire fighters should be trained to avoid walking or standing on any roof structure that appears different from the main roof structure. Skylights typically have a raised frame and may contain screen or wire mesh within the glass or plastic covering. The Occupational Safety and Health Administration (OSHA) General Industry Standard requires that every skylight, floor opening, and hole shall be guarded by a standard skylight screen or a fixed standard railing on all exposed sides [NIOSH 2004; OSHA 1984]. Translucent corrugated roof panels are typically the same size as the surrounding sheet metal roof panels. Translucent corrugated roof panels do not have frames and may be the same or a similar color to the surrounding roof. In low visibility conditions, sounding the roof may be the only way to identify the presence of translucent corrugated roof panels.

In this incident, the Truck 8 crew members briefly sounded the roof before proceeding to other tasks. The first Truck 8 fire fighter to the roof sounded the metal roof in front of the ladder and told the rest of the Truck 8 crew that the roof sounded OK. The senior fire fighter carried a thermal imager, which was used to survey the roof in the area above the window where the dumpster had been located. The Truck 8 lieutenant instructed the Truck 8 fire fighters to walk where the sheet metal screw heads were visible. Note: The areas where the metal roof decking is secured to the underlying support members would typically be the strongest area on the roof. The Truck 8 lieutenant reported that he did not see any hazards on the roof. The Truck 8 engineer was the last member of the Truck 8 crew to climb the ladder to the roof. It was reported that he sounded the roof in front of the ladder, then proceeded to walk up to the peak of the roof. During this investigation, the fire department personnel and NIOSH investigators used a thermal imager to view roofs containing translucent corrugated roof panels at night at approximately 2200 hours. The thermal imager distinctly showed the heat difference between the roof and the translucent roof panels at night, however, it was not known if a thermal imager would be useful later on in the evening/early morning hours, or in winter months, when the temperature fluctuation between the two materials is not as distinct.

Recommendation \#3: Fire departments should train all fire fighters and fire officers to immediately report the presence of translucent corrugated roof panels to incident command as soon as they are detected.

Discussion: The International Association of Fire Chiefs (IAFC), Safety, Health and Survival section, developed the "Rules of Engagement for Structural Fire Fighting." The rules of engagement have been developed to assist both the fire fighter and the incident commander (as well as command team officers) in risk assessment and "Go or No-Go" decisions. The fireground creates a significant risk to fire fighters, and it is the responsibility of the incident commander and command organization officers to minimize fire fighter exposure to unsafe conditions and stop unsafe practices [IAFC 2012].

The IAFC Rules of Engagement can assist the incident commander, company officers, and fire fighters who are at the highest level of risk in assessing their situational awareness. One principle applied in the rules of engagement is that fire fighters and the company officers are the members most at risk for 


\section{Career Fire Fighter/Engineer Dies After Falling Through Translucent Corrugated Roof Panel While Searching for Fire Extension-Colorado}

injury or death and will be the first to identify unsafe conditions and practices. The rules integrate the fire fighter into the risk assessment decision-making process. These members should be the ultimate decision makers as to whether it's safe to proceed with assigned objectives. Where it is not safe to proceed, the rules allow a process for that decision to be made while still maintaining command unity and discipline.

One of the IAFC Rules of Engagement for Firefighter Survival states: "You Are Required to Report Unsafe Practices or Conditions That Can Harm You. Stop, Evaluate, and Decide.” This rule applies the principles of crew resource management by encouraging all fire fighters to apply situational awareness and be responsible for their own safety and that of other fire fighters. In a sense, all fire fighters become the additional eyes and ears of the incident commander and alert him (or the immediate supervisor) to unacceptable situations. No fire attack or building is worth the life of a fire fighter or a preventable (sometimes career ending) injury. The intent of this rule is to allow any member to report a safety concern through a structured process without fear of penalty.

One of the key tenants of the National Fallen Firefighter Foundation (NFFF) is their 16 Life Safety Initiatives. The 16 Firefighter Life Safety Initiatives were jointly developed by representatives of the major fire service constituencies in 2004 at a Firefighter Safety Summit in Tampa, Florida. At that time, the National Fallen Firefighters Foundation was tasked with promulgating the Initiatives throughout the fire service and developing material to support their implementation [NFFF 2004a].

Live Safety Initiative number 4 is "Empowerment-All firefighters must be empowered to stop unsafe practices.” While this may appear to be a challenging or even controversial statement, it simply means that every organization should provide an environment that allows its members to speak up regarding personal and organizational safety, without negative consequences for doing so (within a prescribed context) and without decentralizing the authority of the formal leader. The goal is to have every member fully engaged during an emergency incident with a focus on doing the work in a proficient manner and looking out for one another to avoid injuries and potential line-of-duty deaths [NFFF 2004b].

Every fire fighter is responsible for their individual safety and the safety of other fire fighters. Each fire fighter is responsible for identifying risks and hazards and reporting them. Supervisors are responsible for accepting reports regarding safety concerns without penalizing the fire fighter and properly acting on the report to ensure the safety of fire fighters.

In this incident, the Truck 8 crew members likely did not recognize the potential hazard associated with walking on translucent corrugated roof panels. This type of translucent roof panels were widespread throughout the city. Whenever fire fighters need to work on sheet metal roofs, the presence of translucent corrugated roof panels should be anticipated. Whenever roof crews identify the presence of translucent corrugated roof panels, this information should be immediately communicated to Command and to everyone on the roof. 


\section{Career Fire Fighter/Engineer Dies After Falling Through Translucent Corrugated Roof Panel While Searching for Fire Extension-Colorado}

\section{Recommendation \#4: Fire departments should ensure that all fire fighters are trained in and recognize the importance of situational awareness at all times, including while working on a roof.}

Discussion: The book Essentials of Fire Fighting and Fire Department Operations defines situational awareness as an awareness of the immediate surroundings [IFSTA 2008]. On the fireground, every fire fighter should be trained to be constantly alert for changing and unsafe conditions. This applies not only to the conditions found within a burning structure, but to the exterior fireground as well. Fire fighters may encounter a wide variety of surface features that they must walk across while performing fireground tasks. For example, surfaces may be wet, slippery, ice-covered, uneven, or vegetationcovered or may include debris from the burning structure. Downed power lines, broken or leaking natural gas meters and distribution lines, unstable structures, and other environmental factors are just some of the hazards that may be present on the fireground.

One of the most critical aspects of coordination between crews is maintaining situational awareness. The opposite of situational awareness is tunnel vision where the fire fighters become so focused on fire-fighting or other operational assignments that they fail to sense changes in their environment. Fire fighters can maintain their situational awareness by looking up, down, and around themselves as well as listening for new or unusual sounds and feeling vibrations or movement. Fire fighters and officers should communicate any changes in their environment to other members as well as to the incident commander. Each first responder is responsible for their safety plus the personnel they are working with. Maintaining situational awareness protects against complacency and tunnel vision. The incident scene creates a significant risk to fire fighters, and it is the responsibility of the incident commander and command organization officers to minimize fire fighter exposure to unsafe conditions and stop unsafe practices [IAFC 2012].

In this incident, the Truck 8 engineer was tasked with sizing up and reporting the estimated building dimensions to the incident commander. To obtain the roof dimensions, the engineer walked to the peak of the slightly pitched roof to gain the best vantage point. The Truck 8 lieutenant followed and reported stopping about 5 feet from the peak. The lieutenant and engineer discussed the dimensions of the roof before the engineer reported to Command over the radio, "I'd say approximately 300 x 60 and pretty much rectangular except for the little notch here where the dumpster was.” Immediately after the Truck 8 engineer reported the dimensions, the Truck 8 lieutenant turned away from the engineer and radioed to Command that elevated temperatures had not been detected on the roof using the thermal imager (by the junior and senior fire fighters). The lieutenant was in the middle of making this report when the Truck 8 engineer, after taking one step toward the ladder, fell through the roof. During the investigation, many fire fighters reported that while on-scene they did not immediately know the Truck 8 engineer had fallen through a translucent corrugated roof panel; rather they thought he fell through a weak spot in the roof. Many fire fighters reported, after the fall, even on the inside of the building, on first glance the translucent roof panels blended in with the rest of the roof. It was reported that they could see the translucent roof panels but only after careful observation. During the interviews of the different crews involved in this incident, all of the fire fighters reported they had been on a similar roof at least once. Fire fighters need to be constantly aware of their surroundings and anticipate possible hazards. Whenever fire fighters need to work on sheet metal roofs, the presence of translucent corrugated roof panels should be anticipated. 


\section{Career Fire Fighter/Engineer Dies After Falling Through Translucent Corrugated Roof Panel While Searching for Fire Extension-Colorado}

\section{Recommendation \#5: Fire departments should use risk management principles at all structure fires and emergency response incidents.}

Discussion: While it is recognized that fire fighting is an inherently hazardous occupation, established fire service risk management principles are based on the philosophy that greater risks will be assumed when there are lives to be saved and the level of acceptable risk to fire fighters is much lower when only property is at stake. Interior (inside a structure) offensive fire-fighting operations can increase the risk of traumatic injury and death to fire fighters from structural collapse, burns, asphyxiation, falls, and many other fireground hazards. Established risk management principles suggest that more caution should be exercised in abandoned, vacant, and unoccupied structures and in situations where there is no clear evidence indicating that people are trapped inside a structure and can be saved [NIOSH 2010].

The incident commander, with input from the assigned incident safety officer and/or division/group supervisors, is responsible for evaluating conditions at a structure fire and determining safe tactics for fighting the fire. To accomplish this, the incident commander should use a standardized strategic decision-making model. First, the incident commander should size up the critical fireground factors [Phoenix Fire Department 2009]. The incident commander must make a determination that offensive (interior) operations may be conducted without exceeding a reasonable degree of risk to fire fighters before ordering an offensive attack and must be prepared to discontinue the offensive attack if the risk evaluation changes during the fire-fighting operation. A full range of factors must be considered in making the risk evaluation, including (but not limited to):

- Presence of occupants in the building.

- A realistic evaluation of occupant survivability and rescue potential.

- Size, construction, and use of the building.

- Age and condition of the building.

- Nature and value of building contents.

- Location and extent of the fire within the building.

- Adjacent exposures (structures).

- Fire involvement or compromise of the building's structural components.

- Considerations of fire loading and fire behavior.

- A realistic evaluation of the ability to execute a successful offensive fire attack with the resources that are available [NIOSH 2010; Phoenix Fire Department 2009].

These fireground factors must be weighed against the risk management plan. There is absolute recognition of the fact that fire fighters are routinely exposed to certain known and predictable risks while conducting operations that are directed toward saving property. The incident commander is responsible for recognizing and evaluating those risks and determining whether the level of risk is acceptable or unacceptable. However, risks taken to save property should always be lesser than those to save lives [Grorud 2009; NIOSH 2010]. Risks to fire fighters versus gains in saving lives and property must always be considered when deciding whether to use an offensive or defensive attack. The incident commander should routinely evaluate and reevaluate conditions and radio progress reports in reaching objectives to dispatch on-scene fire fighters. This process allows the incident commander to determine whether to continue or revise the strategy and attack plans. Failure to revise 


\section{Career Fire Fighter/Engineer Dies After Falling Through Translucent Corrugated Roof Panel While Searching for Fire Extension-Colorado}

an inappropriate or outdated attack strategy is likely to result in an elevated risk of death or injury to fire fighters [NFPA 2013; NIOSH 2010].

This incident occurred at approximately 2142 hours at a locked commercial structure. First arriving companies found a dumpster fire located on the exterior with fire impinging upon the exterior wall below a window. The dumpster was pulled away from the building and the fire was quickly extinguished. The time of day, lack of vehicles in the parking lot, and locked doors suggested the structure was vacant. Crews were instructed to search the interior for fire extension and occupants. Truck 8 was instructed to throw a ground ladder to the roof and search for fire extension following standard operating procedures. While on the roof, Truck 8 was instructed to estimate the building dimensions. Immediately after reporting the estimated building dimensions to the incident commander over the radio, the Truck 8 engineer stepped onto a translucent corrugated roof panel that broke under his weight. The Truck 8 engineer fell through the roof and landed on the concrete floor, suffering severe injuries. At the time of this investigation, the fire department did not have building inspection and preplan information in its computer-aided dispatch system, so building dimensions were not available to the incident commander. Fire fighters working on the ground-such as chief's aides, safety officers, apparatus operators, RIT crews, and others-could be used to obtain estimates of building size, construction features, utilities, and other hazards and report this information to command.

\section{Recommendation \#6: Fire departments should conduct pre-incident planning inspections of buildings within their jurisdictions and include this information in computer-aided dispatch systems to facilitate development of safe fireground strategies and tactics.}

Discussion: National Fire Protection Association (NFPA) 1620 Standard for Pre-Incident Planning, 2015 edition, paragraph A.4.9, states, "The pre-incident plan should be the foundation for decision making during an emergency situation and provide important data that will assist the incident commander in developing appropriate strategies and tactics for managing the incident.” This standard also states: "The primary purpose of a pre-incident plan is to help responding personnel effectively manage emergencies with available resources. Pre-incident planning involves evaluating the protection systems, building construction, contents, and operating procedures that can impact emergency operations [NFPA 2015b].” A pre-incident plan identifies deviations from normal operations and can be complex and formal or simply a notation about a particular problem, such as the presence of flammable liquids, explosive hazards, modifications to structural building components, or structural damage from a previous fire [Dunn 2007; NFPA 2015b; NIOSH 1999].

Chapter 5.2.1 states that the entire building size, including the overall height, number of stories, square footage, and approximate or actual year of construction, shall be determined and included in the preincident plan. Chapter 5.2.2.3 states that data regarding roof construction shall be recorded in the preincident plan [NFPA 2015b].

In addition, NFPA 1620 outlines the steps involved in developing, maintaining, and using a preincident plan by breaking the incident down into pre-, during-, and post-incident phases. In the preincident phase, for example, it covers factors such as physical elements and site considerations, occupant considerations, protection systems and water supplies, hydrant locations, and special hazard 


\section{Career Fire Fighter/Engineer Dies After Falling Through Translucent Corrugated Roof Panel While Searching for Fire Extension-Colorado}

considerations. Building characteristics including type of construction, materials used, occupancy, fuel load, roof and floor design, and unusual or distinguishing characteristics should be recorded, shared with other departments who provide mutual aid, and if possible, entered into the dispatcher's computer so that the information is readily available if an incident is reported at the noted address. Since many fire departments have tens and hundreds of thousands of structures within their jurisdiction, making it impossible to preplan them all, priority should be given to those having elevated or unusual fire hazards and life safety considerations.

In this incident, the fire department had conducted both prefire planning and fire safety inspections at the incident site. The most recent prefire planning worksheet identified the roof decking material as metal. The worksheet, dated February 23, 2010, did not identify the presence of translucent corrugated roof panels. Building dimensions were also not recorded. At the time of this incident, the computeraided dispatch system did not contain preplan and fire inspection information. However, the fire department is working toward making this information available through the computer-aided dispatch system in the future.

\section{Recommendation \#7: Fire departments should review all near-miss incidents and, where} appropriate, use these incidents as a learning tool and opportunity to implement new training.

Discussion: The Occupational Safety and Health Administration (OSHA) defines a near miss as an incident in which no property was damaged and no personal injury was sustained, but where, given a slight shift in time or position, damage or injury easily could have occurred. Near misses also may be referred to as close calls, near accidents, accident precursors, injury-free events, and in the case of moving objects, near collisions [Howard 2012].

Whenever a near-miss or minor injury occurs on the job, it can serve as a warning that a more serious incident is waiting to happen. Near misses and resulting inspections may help prevent an injury or even a fatality, but an investigation cannot take place if the near miss is not effectively reported. Therefore, setting up a successful safety management program to ensure near misses are reported and investigated is an important step in reducing occurrences of serious incidents [Howard 2012].

During this investigation, it was reported to NIOSH investigators that a near-miss event involving similar circumstances had occurred at this department in 2012. A fire fighter fell partially through a translucent corrugated fiberglass roof panel but was able to catch himself on the roof decking and was uninjured. The 2012 incident was reported through the National Fire Incident Reporting System but the opportunity to use the incident as a source of training and hazard awareness recognition was not effectively reported. Many successful safety management programs include a process for workers to report near-miss incidents that are then followed up on by management. Fire departments should include a process for investigating near-miss and injury events in their administrative procedures. The goal of any such program should be to improve system reliability and minimize the risk of a more serious incident occurring. 


\section{Career Fire Fighter/Engineer Dies After Falling Through Translucent Corrugated Roof Panel While Searching for Fire Extension-Colorado}

\section{Recommendation \#8: Fire departments should ensure that a separate incident safety officer, independent from the incident commander, is appointed at each structure fire.}

Discussion: According to NFPA 1561 Standard on Emergency Services Incident Management System and Command Safety, 2014 edition, paragraph 5.3.1, "The incident commander shall have overall authority for management of the incident” and paragraph 5.3.2, “The incident commander shall ensure that adequate safety measures are in place.” This shall include overall responsibility for the safety and health of all personnel and for other persons operating within the incident management system. While the incident commander is in overall command at the scene, certain functions must be delegated to ensure adequate scene management is accomplished [NFPA 2014]. According to NFPA 1500 Standard on Fire Department Occupational Safety and Health Program, 2013 edition, paragraph 8.1.6, “As incidents escalate in size and complexity, the incident commander shall divide the incident into tactical-level management components and assign an incident safety officer to assess the incident scene for hazards or potential hazards." These standards indicate that the incident commander is in overall command at the scene but acknowledge that oversight of all operations is difficult. On-scene fire fighter health and safety is best preserved by delegating the function of safety and health oversight to the incident safety officer. Additionally, the incident commander relies upon fire fighters and the incident safety officer to relay feedback on fireground conditions in order to make timely, informed decisions regarding risk versus gain and offensive versus defensive operations. The safety of all personnel on the fireground is directly impacted by clear, concise, and timely communications among mutual aid fire departments, sector command, the incident safety officer, and the incident commander.

Chapter 6 of NFPA 1521 Standard for Fire Department Safety Officer Professional Qualifications defines the role of the incident safety officer at an incident scene and identifies duties such as recon of the fireground and reporting pertinent information back to the incident commander; ensuring the department's accountability system is in place and operational; monitoring radio transmissions and identifying barriers to effective communications; and ensuring established safety zones, collapse zones, hot zones, and other designated hazard areas are communicated to all members on-scene [NFPA 2015a]. Larger fire departments may assign one or more full-time staff officers as safety officers who respond to working fires. In smaller departments, every officer should be prepared to function as the incident safety officer when assigned by the incident commander. The presence of a safety officer does not diminish the responsibility of individual fire fighters and fire officers for safety. The incident safety officer adds a higher level of attention and expertise to help the fire fighters and fire officers. The incident safety officer must have particular expertise in analyzing safety hazards and must know the particular uses and limitations of protective equipment [Dunn 2000].

In this incident, a dedicated incident safety officer could have helped the incident commander in sizing up the incident scene and in identifying the presence of safety hazards, including the presence of translucent corrugated roof panels. A dedicated incident safety officer could have helped the incident commander in estimating the size of the structure as well. 


\section{Career Fire Fighter/Engineer Dies After Falling Through Translucent Corrugated Roof Panel While Searching for Fire Extension-Colorado}

Recommendation \#9: Fire departments should ensure that tools, equipment, and supplies used during emergency responses are adequate for their intended use.

Discussion: During this incident, paramedics and fire fighter/EMTs who assisted with emergency fireground treatment for the Truck 8 engineer reported having trouble cutting through his turnout clothing because the rescue shears being used were too small or not sharp enough to cut through heavy turnout clothing material. Fire fighters reported to NIOSH investigators that it took several minutes to cut off the injured fire fighter's turnout clothing. This has also been reported to NIOSH in other recent investigations [NIOSH 2016a,b]. Fire departments need to ensure that all tools, equipment, and supplies used during emergency responses are adequate and suitable for their intended uses.

Recommendation \#10: Manufacturers, distributors, and installers of translucent corrugated roof panels should ensure that end users are fully aware of the load-bearing limitations associated with these types of roof panels.

Discussion: Manufacturers, distributors, and installers of translucent corrugated roof panels should ensure that these types of panels are prominently marked to indicate their load-bearing limitations. Roof panels that are not intended to be walked upon should be prominently marked to indicate that these panels should not be walked or stepped on.

In this incident, the translucent corrugated roof panels on the roof of the structure where this incident occurred were not marked with any warning.

Recommendation \#11: Municipalities, states, authorities having jurisdiction, and code-setting organizations should consider modifying local, national, and international building codes to require translucent roof panels meet the load bearing and fall resistance requirements of skylights and scuttles as outlined in Chapter 16 of the International Building Code.

Discussion: Translucent corrugated roof panels and similar products are available in many sizes, shapes, and materials. Some products are designed, manufactured, and marketed to be safely walked upon. Others are not intended to be walked upon. In addition to the obvious need for fire fighters to access roofs, workers may be called upon to access roofs for many reasons, including normal or routine building maintenance, utility maintenance, roof repairs, snow removal, and emergency situations.

Building codes should be developed and enforced that take into consideration safely working around translucent corrugated roof panels and similar products. In general, building codes addressing roofs and roof features such as translucent corrugated roof panels, skylights, and similar features should take into consideration anticipated static and dynamic loads for the area, along with general safety issues, such as guarding and limitations for use.

In this incident, the Type II-B noncombustible structure was constructed in 1970. The city building code in effect at that time (1965 city building code) contained a full chapter dedicated to skylights with additional information on transparent or translucent lighting panels in a separate chapter. The code specified that skylights shall be set at least 6 inches above the roof. The roof panel section only 


\section{Career Fire Fighter/Engineer Dies After Falling Through Trans/ucent Corrugated Roof Panel While Searching for Fire Extension-Colorado}

addressed general roof design issues such as spacing and attachment to the building framework [City and County of Denver 1965].

Fire and building code officials should consider modifying the building codes to require the same load bearing capabilities for translucent roof panels as skylights and scuttles. Code officials should also consider modifying codes to require the perimeters of skylights, scuttles, and translucent panels to be identifiable with reflective tape or similar product. These efforts would potentially permit fire fighters to identify the presence of these construction features, allowing them to take necessary precautions. The increased load-carrying capabilities may also protect fire fighters or other trade personnel in reducing the likelihood of a fall.

Recommendation \#12: Municipalities, states, authorities having jurisdiction, and code setting organizations should consider modifying local, national, and international building codes to require the perimeters of skylights, scuttles, and translucent panels be appropriately marked with reflective markings to delineate their locations on a roof.

Discussion: Code officials should consider modifying existing building codes to require the perimeters of skylights, scuttles, and translucent panels to be identifiable with reflective tape or similar product. These efforts would potentially permit fire fighters to identify the presence of these construction features, allowing them to take necessary precautions. The increased load-carrying capabilities may also protect fire fighters, or other trade personnel in the event of a fall.

Recommendation \#13: Fire service and industry representatives should study the current load bearing, and fall resistance, requirements in current Standards and Building Codes to determine if current requirements are sufficient.

Discussion: Load-bearing capabilities are established under ASTM Test Standard E06.51 on FallResistance for Skylights. Currently the standard is under review to increase the weight load capabilities of these features. Industry experts and representatives should move forward with the increased weight resistance capabilities, and translucent panels should be required to meet the same requirements as skylights.

\section{References}

City and County of Denver [1965]. Building code. Denver, CO: City and County of Denver, https://www.denvergov.org/content/dam/denvergov/Portals/696/documents/Denver_Building_Code/Ar chived_Codes/1965_DBC.pdf.

Dunn V [2000]. Command and control of fires and emergencies. Saddle Brook NJ: Fire Engineering Book and Videos.

Dunn V [2007]. Strategy of firefighting. Saddlebrook NJ: Penn Well Publishing Co.

Grorud LJ [2009]. Written comments to NIOSH Public Docket \# 141. March 3, 2009. 


\section{Career Fire Fighter/Engineer Dies After Falling Through Translucent Corrugated Roof Panel While Searching for Fire Extension-Colorado}

Howard K [2012]. Everybody gets to go home in one piece. Safety + Health, January, http://www.safetyandhealthmagazine.com/articles/6843--articles-6843-everybody-gets-to-go-home-inone-piece.

IAFC [2012]. Rules of engagement for structural firefighting. Draft. Fairfax VA: International Association of Fire Chiefs, Safety, Health and Survival Section, http://websites.firecompanies.com/iafcsafety/files/2013/10/Rules_of_Engagement_short_v10_2.12.pdf.

IFSTA [2008]. Essentials of fire fighting and fire department operations. $5^{\text {th }}$ ed. Stillwater Oklahoma: Fire Protection Publications, International Fire Service Training Association.

IFSTA [2010]. Building construction related to the fire service. 3rd ed. Stillwater Oklahoma: Fire Protection Publications, International Fire Service Training Association.

NFFF [2004a]. 16 Firefighter life safety initiatives. Crofton, MD: National Fallen Firefighter Foundation, http://www.everyonegoeshome.com/16-initiatives/.

NFFF [2004b]. Empowerment. In: 16 Life safety initiatives. Crofton, MD: National Fallen Firefighter Foundation, http://www.everyonegoeshome.com/16-initiatives/4-empowerment/.

NFPA [2013]. NFPA 1500 Standard on fire department occupational safety and health program. Quincy, MA: National Fire Protection Association.

NFPA [2014]. NFPA 1561 Standard on emergency services incident management system and command safety. Quincy, MA: National Fire Protection Association.

NFPA [2015a]. NFPA 1521 Standard for fire department safety officer professional qualifications. Quincy, MA: National Fire Protection Association.

NFPA [2015b]. NFPA 1620 Standard for pre-incident planning. Quincy, MA: National Fire Protection Association.

NIOSH [1999]. NIOSH alert: request for assistance in preventing injuries and deaths of fire fighters due to structural collapse. Cincinnati, OH: U.S. Department of Health and Human Services, Centers for Disease Control and Prevention, National Institute for Occupational Safety and Health, DHHS (NIOSH) Publication No. 99-146.

NIOSH [2004]. NIOSH alert: preventing falls of workers through skylights and roof and floor openings. Cincinnati, OH: U.S. Department of Health and Human Services, Centers for Disease Control and Prevention, National Institute for Occupational Safety and Health, DHHS (NIOSH) Publication No. 2004-156, http://www.cdc.gov/niosh/docs/2004-156/.

NIOSH [2010]. NIOSH alert: preventing deaths and injuries of fire fighters using risk management principles at structure fires. Cincinnati, OH: U.S. Department of Health and Human Services, Centers 


\section{Career Fire Fighter/Engineer Dies After Falling Through Translucent Corrugated Roof Panel While Searching for Fire Extension-Colorado}

for Disease Control and Prevention, National Institute for Occupational Safety and Health, DHHS (NIOSH) Publication No. 2010-153, http://www.cdc.gov/niosh/docs/2010-153/.

NIOSH [2016a]. Career fire apparatus operator dies after falling down an unsecured elevator shaft at a 5-story residential structure-Ohio. Morgantown, WV: U.S. Department of Health and Human Services, Centers for Disease Control and Prevention, National Institute for Occupational Safety and Health, F2015-06, http://www.cdc.gov/niosh/fire/reports/face201506.html.

NIOSH [2016b]. Career fire fighter dies after falling down unsecured elevator shaft while searching for the seat of a smoldering fire-Illinois. Draft. Morgantown, WV: U.S. Department of Health and Human Services, Centers for Disease Control and Prevention, National Institute for Occupational Safety and Health, F2015-18.

OSHA [1984]. 29 CFR 1910.23(a) Protection for floor openings. Washington, DC: U.S. Department of Labor, Occupational Safety and Health Administration.

Phoenix Fire Department [2009]. Written comment to NIOSH Docket \#141, March 9.

Weather Underground [2015]. Weather history for KAPA—June, 2015. Atlanta, GA: The Weather Channel Interactive, Inc., http://www.wunderground.com/history/airport/KAPA/2015/6/28/DailyHistory.html?req_city=Denver \&req_state=CO\&req_statename=Colorado\&reqdb.zip=80202\&reqdb.magic=1\&reqdb.wmo=99999.

\section{Investigator Information}

This incident was a joint NIOSH investigation conducted by the Fire Fighter Fatality Investigation and Prevention Program, Surveillance and Field Investigations Branch, Division of Safety Research (DSR), NIOSH located in Morgantown West Virginia; the NIOSH Fire Fighter Fatality Investigation and Prevention Program, Medical Component, located in the Division of Surveillance, Hazard Evaluations and Field Studies (DSHEFS) in Cincinnati Ohio; and the NIOSH Western States Division (WSD), Denver, Colorado office. The NIOSH investigation team consisted of Timothy R. Merinar, Safety Engineer, Dr. Thomas R. Hales, Medical Officer, Corey R. Butler, Occupational Safety and Health Specialist, and Sophie Ridl, Research Assistant.

An expert technical review was provided by Sean DeCrane, Battalion Chief, Cleveland Division of Fire (ret.). A technical review was also provided by the National Fire Protection Association, Public Fire Protection Division.

\section{Additional Information SAFETY ADVISORY}

As part of this investigation, the National Institute for Occupational Safety and Health (NIOSH) Fire Fighter Fatality Investigation and Prevention Program released the publication Safety Advisory: Translucent Corrugated Roof Panels May Contribute to Increased Fall Risk During Roof Operations. 


\section{Career Fire Fighter/Engineer Dies After Falling Through Trans/ucent Corrugated Roof Panel While Searching for Fire Extension-Colorado}

This safety advisory describes the hazards associated with translucent corrugated roof panels and offers recommendations for fire departments and fire fighters to follow while working on roofs. The safety advisory was released to ensure that fire departments and fire fighters were advised of this information in a timely manner. The November 20, 2015, safety advisory can be found at http://www.cdc.gov/niosh/docs/2016-110/pdfs/2016-110.pdf.

\section{NIOSH ALERT}

In 2004, the National Institute for Occupational Safety and Health released the publication NIOSH ALERT: Preventing Falls of Workers Through Skylights and Roof and Floor Openings (DHHS [NIOSH] Publication Number 2004-156). At that time, NIOSH investigations suggested that employers, workers, building owners, skylight designers, and skylight manufacturers may not fully recognize or appreciate the serious fall hazards associated with working near skylights and roof and floor openings. While this publication did not specifically mention translucent corrugated roof panels, many of the recommendations in the Skylight ALERT are also applicable to working around translucent corrugated roof panels. One of the case studies presented in this publication actually involved a farm worker falling through a translucent corrugated roof panel while working to remove snow from the roof. The complete NIOSH publication can be found at http://www.cdc.gov/niosh/docs/2004-156/.

\section{Modern Fire Behavior}

This website is meant to serve as a clearinghouse of news and training information related to Modern Fire Behavior and Modern Building Construction Research, Tactics, and Practices along with actual street experiences. ModernFireBehavior.com is a joint effort between www.FirefighterCloseCalls.com and the Underwriters Laboratories Fire Safety Research Institute. http://modernfirebehavior.com/

\section{IAFC Rules of Engagement for Firefighter Survival}

The international Association of Fire Chiefs (IAFC) is committed to reducing fire fighter fatalities and injuries. As part of that effort, the nearly 1,000 member IAFC Safety, Health and Survival Section has developed the DRAFT “Rules of Engagement for Structural Firefighting” to provide guidance to individual fire fighters and incident commanders, regarding risk and safety issues when operating on the fireground. The intent is to provide a set of modern procedures for structural firefighting to be made available by the IAFC to fire departments as a guide for developing their own standard operating procedures. http://www.iafcsafety.org/downloads/Rules_of_Engagement

\section{IAFF Fire Ground Survival Program}

The purpose of the International Association of Fire Fighters (IAFF) Fire Ground Survival Program is to ensure that training for Mayday prevention and Mayday operations is consistent between all fire fighters, company officers, and chief officers. Fire fighters must be trained to perform potentially lifesaving actions if they become lost, disoriented, injured, low on air, or trapped. Funded by the IAFF and assisted by a grant from the U.S. Department of Homeland Security through the Assistance to Firefighters (FIRE Act) grant program, this comprehensive fireground survival training program applies the lessons learned from fire fighter fatality investigations conducted by the National Institute for Occupational Safety and Health (NIOSH) and has been developed by a committee of subject matter 


\section{Career Fire Fighter/Engineer Dies After Falling Through Translucent Corrugated Roof Panel While Searching for Fire Extension-Colorado}

experts from the IAFF, the International Association of Fire Chiefs (IAFC), and NIOSH. http://www.iaff.org/HS/FGS/FGSIndex.htm

\section{National Institute for Standards and Technology (NIST)_Fire on the Web}

Fire on the Web is a collection of resources from the Building and Fire Research Laboratory's Fire Research Division at NIST. These web pages provide links to fire-related software, experimental fire data, and mpeg/quick time movies of fire tests that can be downloaded and/or viewed with a web browser. http://www.nist.gov/el/fire_research/firesafety/fireontheweb.cfm

\section{Underwriters Laboratories (UL) Firefighter Safety Research Institute (FSRI)}

An online course offered by the UL FSRI highlights the tactical application of nearly two decades of research at the National Institute of Standards and Technology (NIST) and UL on how best to fight modern fires. In 2012, the New York City Fire Department, NIST, and UL FSRI set fire to abandoned townhouses on Governors Island, New York, in a series of experiments to examine tactics for controlling fires and rescuing occupants inside burning homes.

http://www.firecompanies.com/modernfirebehavior/governors\%20island\%20online\%20course/story.ht $\underline{\mathrm{ml}}$

\section{Disclaimer}

Mention of any company or product does not constitute endorsement by the National Institute for Occupational Safety and Health (NIOSH). In addition, citations to websites external to NIOSH do not constitute NIOSH endorsement of the sponsoring organizations or their programs or products.

Furthermore, NIOSH is not responsible for the content of these websites. All web addresses referenced in this document were accessible as of the publication date. 
Career Fire Fighter/Engineer Dies After Falling Through Translucent Corrugated Roof Panel While Searching for Fire Extension-Colorado

\section{Appendix One \\ [Key findings - medical examiners report]}

Deep vein thrombosis

A. Left leg: adherent thrombi occluding the anterior and posterior tibial veins

B. Right leg: adherent thrombi occluding the anterior and posterior tibial veins

Pulmonary embolus

A. Right pulmonary artery: a 19 centimeter $(\mathrm{cm})$ non-adherent thromboembolus extending from the pulmonary trunk into the right pulmonary artery ranging from 0.4 to $1.0 \mathrm{~cm}$ in diameter, completing occluding the artery.

B. Left pulmonary artery: a $6.5 \mathrm{~cm}$ non-adherent thromboembolus extending from the pulmonary trunk into the left pulmonary artery ranging from 0.3 to $1.0 \mathrm{~cm}$ in diameter, partially occluding the artery.

C. First branch of the left pulmonary artery: a $12.5 \mathrm{~cm}$ non-adherent thrombi, $0.8 \mathrm{~cm}$ in diameter, partially occluding the artery.

Recent blunt force injuries to the right upper extremity and truck

A. Compound fractures of the right radius and ulna with lacerations

B. Fractures of the ribs and vertebrae

C. Dislocation of the right elbow with laceration

D. Right brachial artery transection status post multiple surgery interventions:

1. Right arm external fixation

2. Right forearm fasciotomy with skin graft

3. Left thigh skin grafts

4. Numerous right forearm and arm sutured lacerations

E. Multiple abrasions and contusion of the trunk 